The University of Southern Mississippi

The Aquila Digital Community

Master's Theses

Fall 12-2016

\title{
Evaluating the Independent Group Contingency: "Mystery Student" on Improving Behaviors in Head Start Classrooms
}

Jamie Pasqua

University of Southern Mississippi

Follow this and additional works at: https://aquila.usm.edu/masters_theses

Part of the Applied Behavior Analysis Commons, Child Psychology Commons, and the School Psychology Commons

\section{Recommended Citation}

Pasqua, Jamie, "Evaluating the Independent Group Contingency: "Mystery Student" on Improving Behaviors in Head Start Classrooms" (2016). Master's Theses. 270.

https://aquila.usm.edu/masters_theses/270

This Masters Thesis is brought to you for free and open access by The Aquila Digital Community. It has been accepted for inclusion in Master's Theses by an authorized administrator of The Aquila Digital Community. For more information, please contact Joshua.Cromwell@usm.edu. 


\title{
EVALUATING THE INDEPENDENT GROUP CONTINGENCY: “MYSTERY STUDENT” ON IMPROVING BEHAVIORS IN HEAD START CLASSROOMS \\ by \\ Jamie Lynn Pasqua
}

\begin{abstract}
A Thesis
Submitted to the Graduate School and the Department of Psychology at The University of Southern Mississippi in Partial Fulfillment of the Requirements for the Degree of Master of Arts
\end{abstract}

Approved:

Dr. Brad A. Dufrene, Committee Chair

Professor, Psychology

Dr. Keith Radley., Committee Member

Assistant Professor, Psychology

Dr. Evan H. Dart, Committee Member

Assistant Professor, Psychology

Dr. Karen S. Coats

Dean of the Graduate School 


\section{COPYRIGHT BY}

Jamie Lynn Pasqua

2016

Published by the Graduate School

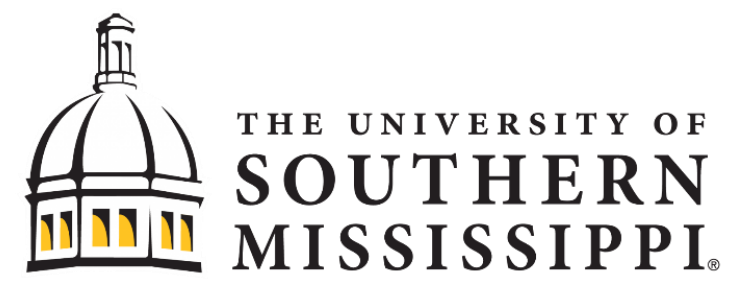




\begin{abstract}
EVALUATING THE INDEPENDENT GROUP CONTINGENCY: “MYSTERY STUDENT” ON IMPROVING BEHAVIORS IN HEAD START CLASSROOMS by Jamie Lynn Pasqua
\end{abstract}

December 2016

An increasing number of preschool children exhibit challenging behavior in the classroom. Head Start children are particularly at risk for emotional and behavioral disorders due to numerous risk factors. Unfortunately, some preschool teachers are ill equipped to manage the challenging behaviors that preschool children exhibit. The current study investigated the effects of the group contingency, "Mystery Student," on improving preschool classroom behaviors. The Mystery Student intervention is a novel, independent group contingency, with an added randomized component. An ABAB reversal design was employed to determine how effective the Mystery Student intervention was at decreasing the disruptive behaviors and increasing the appropriate behaviors in three Head Start classrooms. Results indicated that class-wide aggregate disruptive behavior was reduced and class-wide aggregate appropriate behavior increased during the intervention phases for all three classrooms. Furthermore, teachers rated the Mystery Study intervention as acceptable. Results of this study increase the limited research base on group contingencies in preschool settings, suggest independent group contingencies are developmentally appropriate for young children and may provide practitioners and teachers with an additional intervention strategy for preschool populations. 


\section{ACKNOWLEDGMENTS}

Special thanks goes out to my thesis committee chair, Dr. Brad Dufrene, and my committee members, Dr. Keith Radley and Dr. Evan Dart for their extensive support and their expert advice for this research project. Additionally, I would like to thank the Head Start Agency that supported the implementation of this project and their continued support and service provision for underprivileged preschoolers and their families in the community. 


\section{TABLE OF CONTENTS}

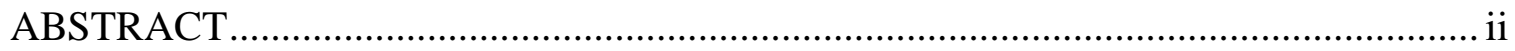

ACKNOWLEDGMENTS .............................................................................. ii

LIST OF TABLES ….................................................................................... vii

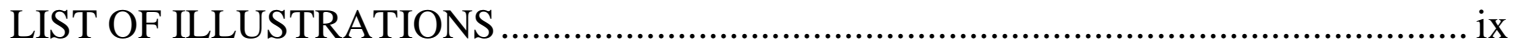

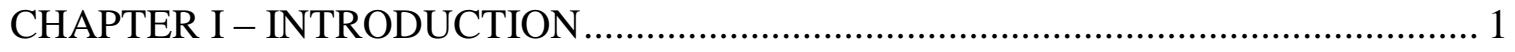



Positive Behavior Interventions and Supports in Preschool Settings .......................... 2



Comparison Studies of Group Contingencies...................................................... 6

Group Contingencies in Preschool Settings ............................................................ 8

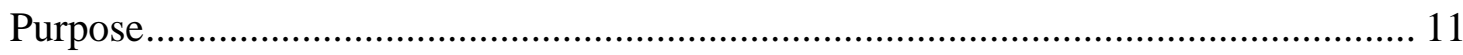

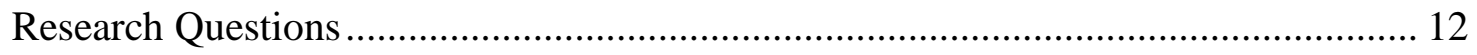



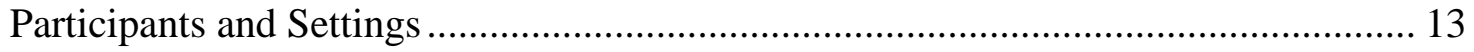

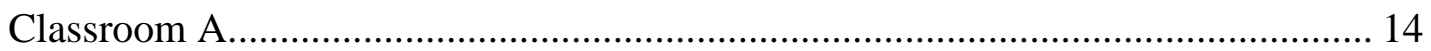

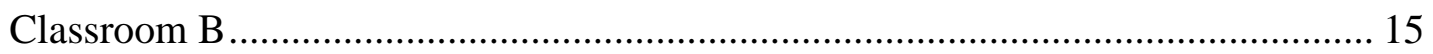

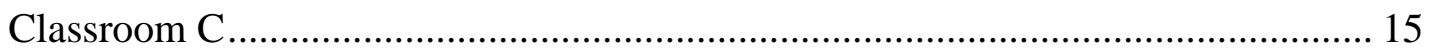

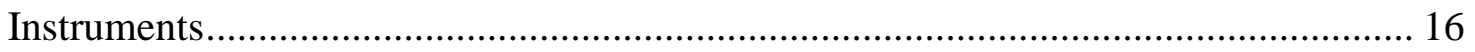

Class-wide Daily Behavior Reports (C-DBR) .................................................... 16 
Behavior Intervention Rating Scale (BIRS)

Materials 18

MotivAider®. 18

Prize Box

Name Bag. 19

Teacher Data Sheet 19

Dependent Measures and Data Collection Procedures ......................................... 20

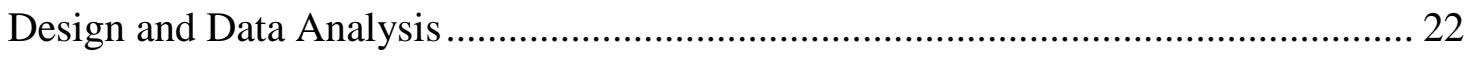

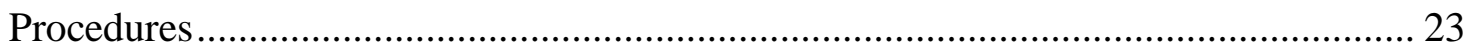

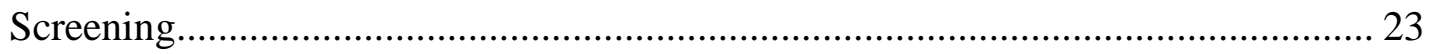

Behavior Identification and DBR Training Meeting …..................................... 23

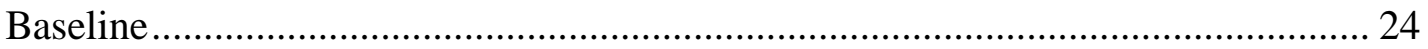

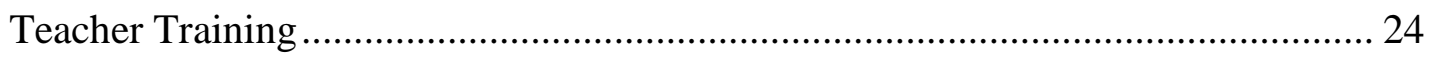

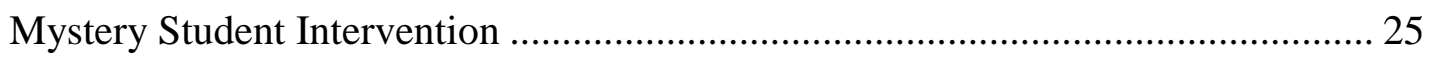





Procedural Integrity and Treatment Integrity ................................................ 28

CHAPTER III - RESULTS .......................................................................... 30

Disruptive and Academically Engaged Behavior ................................................ 30




Classroom B 34

Classroom C...... 34

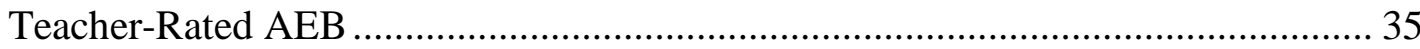

Social Validity of Mystery Student....................................................................... 36



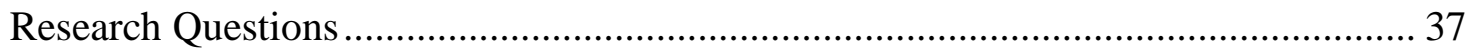

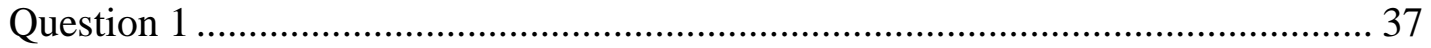



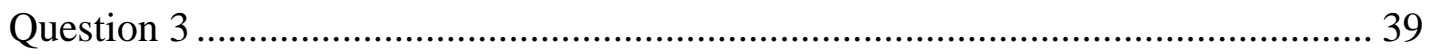

Limitations and Future Directions ..................................................................... 39

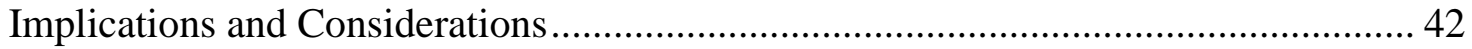

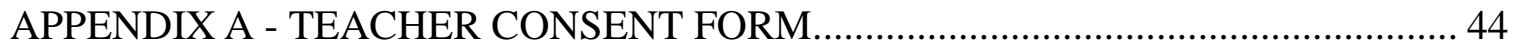

APPENDIX B - IRB APPROVAL LETTER .................................................... 46

APPENDIX C - CLASS-WIDE DAILY BEHAVIOR RATING ................................ 47

APPENDIX D - BEHAVIOR INTERVENTION RATING SCALE ............................ 48

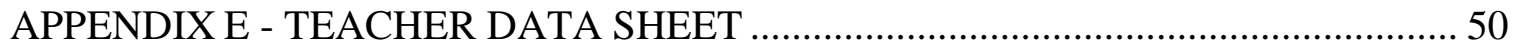

APPENDIX F - DATA COLLECTION SHEET FOR DIRECT OBSERVATION........ 51

APPENDIX G - PROCEDURAL INTEGRITY CHECKLIST FOR TEACHER DBR

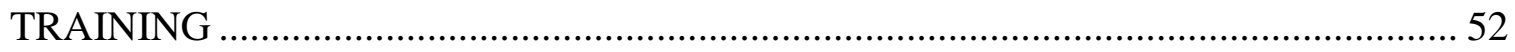


APPENDIX H - SCRIPTED INSTRUCTION SHEET FOR MYSTERY STUDENT

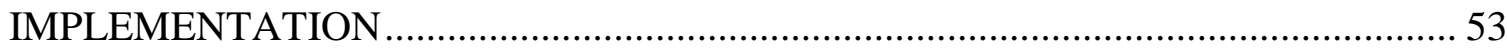

APPENDIX I - PROCEDURAL INTEGRITY CHECKLIST FOR TEACHER

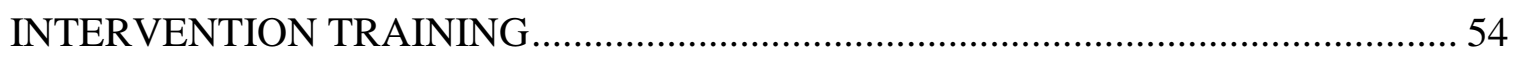

APPENDIX J - TREATMENT INTEGRITY CHECKLIST ........................................ 55

APPENDIX K - PROCEDURAL INTEGRITY CHECKLIST FOR BASELINE AND

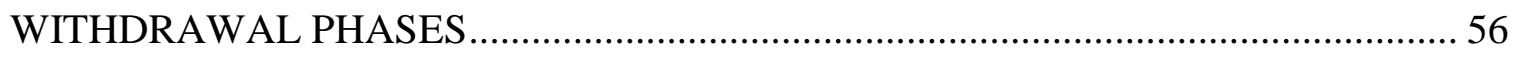

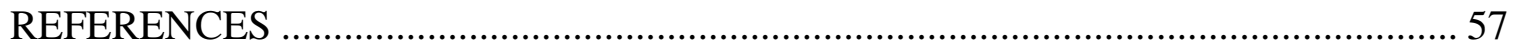




\section{LIST OF TABLES}

Table 1 AEB and DB from baseline to intervention (Tau-U Effect Sizes with 90\% CI). 30

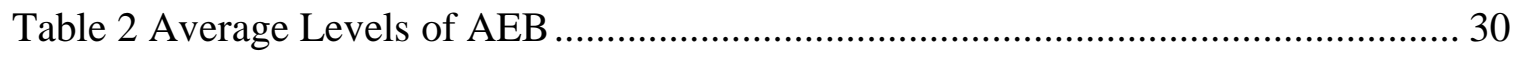






\section{LIST OF ILLUSTRATIONS}



Figure 2. Teacher-Rated Class-wide Appropriately Engaged Behavior ........................ 32 


\section{CHAPTER I - INTRODUCTION}

Preschool Attendance

Preschool attendance has shown to be beneficial for promoting school readiness, language acquisition, and social-emotional development in young children (Entwisle, 1995; Schweinhart, 1994). Although preschool is generally a positive and beneficial experience, an alarming rate of children experience severe emotional and behavioral difficulties. Specifically, research has demonstrated that upwards of $30 \%$ of all preschool children experience some form of an Emotional and Behavioral Disorder (EBD) and other related difficulties such as, anxiety, depression, aggression, noncompliance, and tantrums (Egger \& Angold, 2006; Lavigne, LeBailly, Hopkins, Gouze, \& Binns, 2009; Wichstrom et al., 2012). These rates are highest (30\%) in preschool children who come from low socioeconomic status (SES) households, such as those enrolled in Head Start, compared to populations with wide ranging SES statuses (3-6\%; Campbell, 1990; Feil, Small, Forness, \& Serna, 2005; Powell, Fixsen, Dunlap, Smith, \& Fox, 2007; Qi \& Kaiser, 2003). These higher rates have been linked to risk factors across families and school systems. For example, economically disadvantaged families endure risk factors such as, high unemployment, poor living conditions, high stress levels, minimal education, medical health problems, and high rates of mobility. Furthermore, the preschool programs that predominately serve disadvantaged and minority children tend to receive less funding (Murnane \& Steele, 2007), which results in poorly resourced and performing early education programs that are unable to adequately meet the needs of the children (Murnane \& Steele, 2007; U.S. Department of Health \& Human Services, 2015). 
The consequences to children with early onset EMDs are both immediate and long-standing including, inadequate academic instruction (Snell, Berlin, Vorhees, Stanton-Chapman, \& Hadden, 2012,), negative teacher-child relationships (Qi, Kaiser, \& Milan, 2006), and expulsion rates that are up to three times to that of K-12 students (Gilliam, 2005). Furthermore, longitudinal research suggests that the early onset of EMDs puts children at an increased risk for future school failure, juvenile delinquency, peer rejection, and development of mental disorders during adulthood (Campbell, 1990; Dunlap, Strain, \& Fox, 2006; Larmar \& Gatfield, 2006; Webster-Stratton, Reil, \& Stoolmiller, 2008; Whitted, 2011). The concerns amongst parents, childcare providers, teachers (Bruns \& Mogharreban, 2007; Campbell, 1995), policy makers (U.S. Department of Health \& Human Services, 2015), researchers, and practitioners, are well warranted. Although problematic, these concerns have resulted in an increased focus on the identification, investigation, and the implementation of effective intervention practices in early childhood education settings (Conroy, Dunlap, Clarke, \& Alter, 2005; Pretti-Frontczak et al., 2013; U.S. Department of Health and Human Services, 2015).

Positive Behavior Interventions and Supports in Preschool Settings In order to adjust the developmental trajectory of preschool children exhibiting early onset of emotional and behavioral difficulties, it is imperative to implement early identification and intervention practices. Fortunately, research and practice on early intervention frameworks that target preschool-aged children's social, emotional, and behavioral skill repertoires are the rise and showing promising effects on preschool children's behaviors (Cooper, Heron, \& Heward, 2007; Raver et al., 2009; WebsterStratton et al., 2004). Specifically, policy makers, researchers and school-based 
professionals have disseminated the effectiveness of multi-tiered intervention frameworks to prevent, support and address the social-emotional, behavioral, and academic needs of young children (Conroy et al., 2005; Individuals with Disabilities Education Act, 2004; U.S. Department of Health and Human Services, 2015; Worcester, Nesman, Raffaele Mendez, \& Keller, 2008). One potential example of such a framework is Program-wide Positive Behavior Interventions and Supports (PW-PBIS) which is an adaptation of School-wide Positive Behavior Interventions and Supports (SW-PBIS; Sugai \& Horner, 2006). While the implementation of PBIS frameworks have largely been in elementary and secondary school settings, adaptations of such a framework within early childhood settings is a growing trend in both research and practice and is proving to result in positive outcomes (Benedict, Horner, \& Squires, 2007; Dunlap \& Fox, 2009; Fox \& Little, 2001; Stormont, Lewis, \& Beckner, 2005). While they differ in the populations in which they are implemented with, SW-PBIS and PW-PBIS share core elements including, the implementation of evidence-based practices along a continuum of supports, the use of a measurement system that facilitates data to assist in the identification student who require more intensive intervention efforts, and the primary goals to prevent challenging behaviors and increase children's social, emotional, and behavioral competencies (Benedict, et al, 2007; Dunlap \& Fox, 2009; Fox \& Little, 2001). The continuum of supports exists within three tiers, with each tier consisting of more intensive interventions efforts (Fox et al., 2010; Horner et al., 2010).

While the research is emerging on the implementation of PBIS frameworks in preschool settings, the majority of specific analyses on interventions within each tier is limited to those that are intensive, individualized, and comprehensive. There is evidence 
to suggest teachers can successfully implement these interventions with preschool children (Dufrene, Doggett, Henington, \& Watson, 2007; LaBrot, Dufrene, Radley, \& Pasqua, 2016), as well as evidence to suggest such interventions can improve preschoolaged children's social, emotional, and behavioral skill repertoires (Raver et al., 2009). Unfortunately, there is also a substantial amount of research suggesting teachers are less likely to implement individualized interventions due to their complexity and involvedness (Blair, Fox, \& Lentini, 2010; Dunlap \& Fox, 2011; Hoover, Kubicek, Rosenberg, Zundel, \& Rosenberg, 2012; Vinh, Strain, Davidon, \& Smith, 2016; Von Brock \& Elliott, 1987). Teachers may not view individual interventions as being feasible for several reasons, such as; a lack of effective behavior management skills and training, the intensive individualized attention required to implement, and the amount of time and resources teachers must exhaust, especially for those who have multiple children receiving intervention services (Albers \& Greer, 1991; Bruns \& Mogharreban, 2007; Litow \& Pomroy, 1975; Quesenberry, Hemmeter, \& Ostrosky, 2011). Thus, there is a need for interventions in preschool classrooms that are acceptable, feasible, effective and efficient. In an attempt to remediate these issues, researchers and practitioners suggest the use of interventions that prevent and treat the behaviors of multiple children and exist in the tiers that exist within a PBIS framework. A viable option to meet those recommendations is the implementation of group contingencies in preschool classrooms as they have shown to be effective and practical in managing multiple challenging behaviors in $\mathrm{K}-12$ classrooms (Maggin, Johnson, Chafouleas, Ruberto, \& Berggren, 2012; Skinner, Skinner, \& Burton, 2009; Stage \& Quiroz, 1997; Tingstrom, Sterling-Turner, \& Wilczynski, 2006). 


\section{Group Contingencies}

Group contingencies apply consequences that are shared across members of a group; however, the delivery of reinforcement can be based on the performance of one, some, or all members of that group (Litow \& Pomroy, 1975). A group contingency takes one of three forms including, independent, interdependent and dependent. In an independent group contingency there is a shared performance criterion (e.g., homework assignment completion) and access to reinforcement is only given to those individuals who meet the performance criterion (Cooper, Heron, \& Heward, 2007; Litow \& Pumroy, 1975). Interdependent group contingencies also involve shared performance criterion, however, the delivery of reinforcement is based on the group's behavior as a whole (Litow \& Pomroy, 1975). That is, all members of the group receive the reinforce consequence if the group's average performance meets a specific criterion. Interdependent group contingencies can be implemented with one group (i.e., entire class) or by creating multiple subgroups such as teams (Gresham \& Gresham, 1982; Litow \& Pumroy, 1975). In dependent group contingencies, access to reinforcement for an entire group of individuals, is contingent on the performance of a selected student or of a selected sub group of individuals (Gresham \& Gresham, 1982; Litow \& Pumroy, 1975). In other words, individuals within a group can access reinforcement if the preselected student(s) meets the criteria. Overall, it has been shown that independent, dependent, and interdependent group contingencies are effective for managing classroom behavior (Kazdin \& Geesey, 1977; Maggin et al., 2012; Shapiro, Albright, \& Ager, 1986;

Stage \& Quiroz, 1997). Although some existing studies that have investigated the relative differences between the three group contingency forms, they are limited in number, and 
the results are mixed, (Gresham \& Gresham, 1982; Little, Akin-Little, \& O’Neill, 2015; Theodore, Bray, \& Kehle, 2004).

\section{Comparison Studies of Group Contingencies}

Gresham and Gresham (1982) compared the relative effectiveness of each type of group contingency on reducing disruptive behaviors of 12 students in a self-contained classroom utilizing an $\mathrm{A} / \mathrm{B} / \mathrm{C} / \mathrm{D} / \mathrm{D} / \mathrm{B} / \mathrm{C} / \mathrm{D}$ reversal design. Results from this study indicated that all three group contingencies decreased disruptive behaviors; however, the interdependent and dependent forms resulted in a slightly greater decline in disruptive behavior than the independent form (Gresham \& Gresham, 1982). However, it cannot be concluded that superiority truly existed due to the noted procedural violations during the independent group contingency and the potential carry-over effects from the sequential phase order (Gresham \& Gresham, 1982). Theodore et al. (2004) sought to compare the differential treatment effects of independent, dependent and interdependent group contingencies on the disruptive behavior of a self-contained, high school classroom by employing an alternating treatment design (ATD) to make an initial comparison. The authors reported that there were no differential treatment effects between independent, dependent, and interdependent group contingencies.

Recently, there have been two quantitative syntheses of the group contingencies literature (Little et al., 2015; Maggin et al., 2012). Maggin and colleagues (2012) quantitatively synthesized a large body of research that utilized group contingencies within classrooms in order to determine if such interventions can be considered evidencebased. Specifically, Maggin and Colleagues (2012) applied the What Works Clearinghouse (WWC; Kratochwill et al., 2010) procedures for single-case research, on 
the group contingency literature. Results from their analysis suggested that group contingency interventions demonstrate sufficient empirical support to be considered an evidence-based strategy. These results are consistent with those of earlier reviews that also indicate group contingencies can be considered an empirically grounded intervention option for improving behaviors in classroom settings (Litow \& Pumroy, 1975; Stage \& Quiroz, 1997).

The utilization of group contingencies gained additional support when Little and colleagues (2015) conducted a meta-analysis of group contingency literature published between 1980 and 2010. Specifically, baseline means, standard deviations, and treatment means were extracted from the selected studies and then converted individual study statistics into effect size estimates. In particularly, Little and colleagues (2015) calculated a variation of Cohen's (1988) $d$ statistic to quantify the magnitude of change in level of performance (Beeson \& Robey, 2006; Busk \& Serlin, 1992). They found a strong effect size of 3.41, which further demonstrates the efficacy of group contingencies (Little et al., 2015). Finally, Little et al. (2015) found strong effect sizes across all three types of group contingencies with only small differences [dependent group contingencies $(\mathrm{ES}=3.75, n$ $=11$ ), independent group contingencies $(\mathrm{ES}=3.27, n=8)$, and interdependent group contingencies $(\mathrm{ES}=2.88, n=35)]$. Although research has not clearly demonstrated differential effects between independent, dependent and interdependent group contingencies, there is substantial evidence suggesting that all forms are effective and have associated advantages.

Numerous advantages have been associated with the implementation of group contingencies and, in sum, the literature suggests that these intervention procedures are 
cost-effective, time efficient, can be implemented with ease, are rated acceptable by teachers, has procedural flexibility, and produces a variety of behavioral changes (Cooper et al., 2007; Hayes, 1976; Heering \& Wilder, 2006; Little et al., 2015; Maggin et al., 2012; Moore, Waguespack, Wickstrom, Witt, \& Gaydos, 1994; Skinner et al., 2009). While the use of group contingencies has enormous evidence to support their use, it is important to note that the published literature is incredibly limited with regard to studies conducted in early education settings (Filcheck, \& McNeil, 2004; Hoag, 2007; Hunt, 2013; Kohler et al., 1995; Ling \& Barnett, 2013; Maus, 2007; Murphy, Theodore, Aloiso, Alric-Edwards, \& Hughes, 2007; Pasqua, Dart, Radley, 2016; Pokorski, Barton, \& Ledford, 2016; Reitman Murphy, Hupp, \& O’Callaghan, 2004; Swiezy, Matson, \& Box, 1992).

\section{Group Contingencies in Preschool Settings}

Group contingencies may be a promising practice in early education settings, particularly in those settings that serve disadvantaged populations, which include high rates of children who exhibit early emotional and behavioral problems. Additionally, group contingencies are procedurally flexible therefore, it is possible to modify the components to match the developmental level of preschoolers. Additionally, the group contingencies literature indicates that group contingencies can be a relevant component embedded within positive behavioral interventions and supports (PBIS) systems (Molloy, Moore, Trail, Van Epps, \& Hopfer, 2013).

A recent publication by Pokorski and colleagues (2016) conducted an extensive literature search for group-contingency programs with preschool populations and then synthesized the results for a total of 10 studies $(7$ peer-reviewed publications 
and 3 dissertations) that were published between 1971 and 2013 (Pokorski et al., 2016). Pokorski and colleagues (2016) sought to identify and report descriptive characteristics of these studies so as to evaluate the value of using group behavior management systems with preschool children. A total of 28 variables were extracted and analyzed so as to assess the following areas: study descriptors (e.g., participants, settings, implementers), topography and measurement systems of dependent variables, intervention characteristics and components (e.g., group contingency type, pre-intervention participant training, use of visual components), reward type and category (e.g., social, tangible, activity), reward selection method, results, and study rigor. In order to evaluate the quality and the extent of internal and external validity for these studies, researchers examined measurements of Inter-observer Agreement (IOA), procedural fidelity, generalization, and social validity. Study quality was also assessed by the application of a systematic protocol based on Kratochwill et al.'s (2013) single case design standards and Horner and colleagues' (2005) single case quality indicators. Finally, outcomes were examined by visual analysis (trend, level and variability) and the application of a success estimate ratio for single case research.

Six of the ten studies investigated the use of an interdependent type of group contingency, three of the ten studies looked at the use of an independent group contingency form, and one study investigated a dependent contingency. Eight of the ten studies reported participants' age (in years) which ranged from 3 to 6 years; the remaining two studies did not report actual ages but defined participants as being “preschool aged” (Ling \& Barnett, 2013; Reitman et al., 2004). For studies that reported info on the reward systems, five used unknown or "mystery" rewards (Filcheck \& 
McNeil, 2004; Ling \& Barnett, 2013; Maus, 2001; Murphy et al., 2007; Reitman et al., 2004) and two used rewards that were known to the participants prior to sessions (Hunt, 2013; Sweizy et al., 1992).

In terms of study rigor, authors designated that the synthesized literature, "generally displayed low to moderate quality" (Pokorski et al., 2016) for several reasons. First, all ten studies obtained IOA data, nine of which were above $80 \%$ however, only two studies (Hunt, 2013, Ling \& Barnett, 2013) specifically reported that IOA data were collected reliably across all conditions and participants. Another factor that was considered when judging study rigor was whether or not social actability was obtained; six of ten studies accomplished this. Authors concluded that, overall, the synthesized research did not meet contemporary recommendations for procedural fidelity (Horner et al., 2005) particularly because only three studies (Filcheck, 2004; Hunt, 2013; Ling \& Barnett, 2013) collected fidelity data for at least $20 \%$ of sessions. Finally, only four studies measured and assessed generalization (Filcheck, 2004; Herman \& Tramontana, 1971; Sweizy et al., 1992) and only one assessed maintenance (Filcheck, 2004) which decreases the quality of study rigor.

Outcome analysis recognized variations across the studies' results in terms of the number of functional relation demonstrations. (range; $1-8$ ). Specifically, only nine of the 34 attempts to demonstrate a functional relation was successful (26\%) were successful (Pokorski et al., 2016). Outcome analysis also identified limitations related to the adequacy of baseline condition descriptions

The overall results of the synthesis suggested that group-contingencies with preschool children were effective at producing positive behavioral changes and did not 
produce negative effects, which is consistent with previous analyses on group contingencies (Little et al., 2015; Maggin et al., 2012). However, the authors also concluded that there is still a need for more rigorous research on the use of group contingencies with preschoolers to substantiate their findings.

\section{Purpose}

Overall, the preschool group contingency literature is incredibly limited (Filcheck \& McNeil, 2004; Hoag, 2007; Hunt, 2013; Kohler et al., 1995; Ling \& Barnett, 2013; Maus, 2007; Murphy et al., 2007; Pasqua et al., 2016; Pokorski et al., 2016; Reitman et al., 2004; Swiezy et al., 1992). Moreover, the preschool group contingency literature largely includes interdependent group contingencies. Specifically, more than $60 \%$ of the group contingencies investigated are interdependent group contingencies (Hoag, 2007; Hunt, 2013; Kohler et al., 1995; Ling \& Barnett, 2013; Murphy et al., 2007; Pasqua et al., 2016; Swiezy et al., 1992); while the remaining studies included two independent group investigations (Filcheck, 2004; Maus, 2007) and only one dependent contingency investigation (Reitman et al., 2004). Because independent group contingencies require each individual to reach the pre- determined criterion (i.e., a direct cause-and-effect contingency) they should, theoretically, be developmentally appropriate interventions for preschool-aged children (Pokorski et al., 2016); however, more research is needed to demonstrate the efficacy of independent group contingencies in preschool.

Providing teachers with feasible, efficient, and effective interventions to address challenging behavior in preschool classrooms, is crucial to decrease challenging behaviors, increase appropriate behavior, and reduce preschool expulsions (Hemmeter, Fox, Jack, \& Broyles, 2007; Hemmenter \& Santos, 2008). The use of group 
contingencies may fulfill this need. Therefore, the purpose of the current study is to extend the literature on group contingencies in preschool settings by providing an additional demonstration of the efficacy of an independent group contingency in three preschool classrooms. The independent group contingency investigated in the current study is called Mystery Student. Specifically, the Mystery Student intervention is a novel independent group continegncey that included a randomized target student component. It was hypothesized that the Mystery Student intervention would decrease challenging behaviors, increase appropriate behavior and be deemed acceptable by teachers in preschool classrooms.

\section{Research Questions}

1. Does the Mystery Student intervention reduce disruptive behaviors in Head Start classrooms?

2. Does the Mystery Student intervention increase appropriately engaged behaviors in Head Start classrooms?

3. Is the Mystery Student intervention socially valid to Head Start teachers? 


\section{CHAPTER II - METHODS \\ Participants and Settings}

Three lead and three assistant Head Start (HS) teachers and their respective classrooms, participated in the current study. Each HS classroom was part of an agency that operated multiple Early Head Start and Head Start centers in one rural county in a southeastern state. Classrooms A \& B were located within the same HS center, which housed 16 HS classrooms and 5 Early HS classrooms, while Classroom C was a single classroom center located within a public elementary school (Classroom C). The child population for the entire agency was $73 \%$ African American, 13\% Caucasian, $13 \%$ Hispanic or Asian, and 1\% unspecified. All children were from families with income at or below the federally defined poverty line, as part of the federal Head Start entry criteria. SWPBIS procedures were in place in all classrooms throughout the agency. Specifically, results from the Preschool-Wide Evaluation Tool (PreSET; Steed, Pomerleau, \& Horner, 2012) indicated this Head Start agency implemented an average of $60 \%$ of the core SWPBIS features at the time of administration.

Participating classes were recruited based on either; high levels of behavior incident reports submitted by the same teacher for several different children (Classroom A), administrator-reported concerns regarding the lack of effective classroom behavior management strategies exhibited by teachers and associated high levels of class-wide disruptive behavior (Classrooms B), or teachers' self-referral regarding high levels of challenging behaviors during small-group academic instruction (Classroom C). After teachers indicated a need for intervention services, teachers consented to participate in the study (Appendix A). Following consent, a screen-in observation of student behavior 
was conducted in order to determine if each classroom met the predetermined inclusion criterion, a minimum of $30 \%$ of intervals in which AEB was observed. This study did not include data collection for any individual student. Rather, aggregate classroom behavior data were collected. The University’s Institutional Review Board (IRB) approved all procedures prior to the recruitment of participants and data collection (see Appendix B).

\section{Classroom A}

The lead teacher in this class, Teacher A1, was a 32-year-old African American female, who held a Master's in Early Childhood Education degree, and had been teaching Head Start children for 4 years. Teacher A1's assistant teacher, Teacher A2, was a 34year-old African American female, who held an Associate's degree in early education and had been teaching in Head Start for 3 years. Teachers qualified for services due to a high level of behavior incident reports submitted by the teachers for several different children. Both teachers indicated that several children in their classroom engaged in disruptive behaviors during large group instruction (i.e., carpet-time). Specifically, children engaged in, inappropriate vocalizations, out of area behavior, and playing with objects not related to the lesson during carpet-time. Furthermore, it was reported that these behaviors were disruptive and interrupted instruction. Teachers reported that, keeping their hands and feet to themselves, active participation in carpet time lessons, speaking only when permissible, and refraining from manipulating objects unrelated to the ongoing carpet time activity, were all appropriate carpet-time behaviors they desired the children to demonstrate. Classroom A was composed of 20 students; 16 students were African American, 1 student was Caucasian and 3 students were Hispanic. Two of 
the students in the class had a special education ruling; disability categories included developmental delay, and speech and language.

\section{Classroom B}

The lead teacher in this class, Teacher B1, was a 28-year-old African American female, who held a Bachelor of Arts Degree in Child and Family Studies, and had been teaching Head Start children for 3 years. Teacher B1'a assistant teacher, Teacher B2, was a 43 year old African American female, who held an Bachelor of Arts Degree in Early Childhood Education and had been teaching in Head Start for 14 years. Both teachers indicated that several children engaged in disruptive behaviors during center time, a free play period where children engage in various activities within a specified center (e.g., housekeeping area, art area, computer, etc.). Specifically, teachers reported children, running around the classroom, leaving designated area without permission, aggressing towards others and objects, and the inappropriate use of materials in each center (e.g., standing on furniture and throwing objects). Teachers wanted children to ask permission before leaving a center, walk in the classroom, use materials and furniture appropriately, and keep their hands and feet to themselves. Classroom B was composed of 20 students; 16 students were African American, and 4 students were Hispanic.

\section{Classroom C}

The lead teacher in this class, Teacher C1, was a 31-year-old African American female, who held a Bachelor of Arts Degree in Psychology, and was in her first year of teaching Head Start children. Teacher C1's assistant teacher, Teacher C2, was a 39-year old African American female, who had been a teacher in Head Start settings for three years, Teacher $\mathrm{C} 2$ withdrew from the study before the researcher was able to obtain 
information related to her degree. Like Classroom A, both teachers indicated that several children engage in disruptive behaviors during large group instruction (i.e., carpet-time). Specifically, children engaged in, inappropriate vocalizations, out of area behavior, minor aggression, and playing with objects not related to the lesson. Teachers reported that, during carpet-time, they wanted children to keep their hands and feet to themselves, actively participant in carpet time lessons, speak only when given permission (or when they were called on), and refrain from manipulating objects unrelated to the activity. Classroom C was composed of 17 students; 15 students were African American, 1 student was Caucasian and 1 student was Hispanic. Two of the students in the class had a special education ruling.

\section{Instruments}

Class-wide Daily Behavior Reports (C-DBR)

C-DBR's were used to assess teachers' perceptions of aggregate, class-wide AEB during the target activity. The C-DBR's is a modified version of direct behavior rating (DBR) methods described by Chafouleas, Riley-Tillman, and Christ (2009). DBR's serve as flexible tools to measure multiple or single behaviors (Chafouleas, McDougal, RileyTillman, Panahon, \& Hilt, 2005; Christ, Riley-Tillman, \& Chafouleas, 2009) for purposes of assessment, intervention monitoring, and communication (Chafouleas et al., 2009). Research has shown that DBR's; are perceived as acceptable tools by teachers for assessment and monitoring purposes (Chafouleas, Riley-Tillman, \& Sassu, 2006), can yield reliable behavior measurements that are comparable to systematic observations (Chafouleas, Kilgus, \& Hernandez 2009; Chafouleas, Sanetti, Kilgus, \& Maggin, 2012; Riley-Tillman, Chafouleas, Briesch, \& Eckert, 2008; Volpe \& Briesch, 2012), and may 
lend to similar intervention decisions to decisions that would have been made based off of systematic observations (Riley-Tillman et al., 2008). The majority of the DBR's used in previous research are those focused on the assessment of individual students; however, Riley-Tillman, Methe, and Weegar (2009) designed a DBR that assessed aggregate classroom behavior in order to determine the class' response to a group contingency. The researchers found the class-wide DBR an adequate tool to measure behavior changes at a group-level and that the DBR data were consistent with data collected via systematic direct observations. Results obtained by Riley-Tillman and colleagues provide an important contribution to the DBR literature and suggest that DBR's can be utilized to assess intervention effects at the classroom level (2009).

DBR's are commonly defined by being direct, behavior specific, and include a rating component in which individual perceptions of behavior are quantified (Chafouleas, et al., 2009; Christ et al., 2009); therefore, the C-DBR's used in the present study were developed to be consistent with those defining characteristics. Specifically, the C-DBR's were direct in that teachers rated the classroom's behavior immediately after the behaviors occurred within the same location they occurred, they were behavior specific in that they explicitly listed behaviors that were operationally defined and finally, C-DBR's included a rating component that measured (and quantified) teachers' perceptions of class-wide behavior. An example DBR used in this study can be seen in Appendix C.

The behaviors listed on the C-DBR's were specific to each classroom's referral concern and included teacher-desired appropriate behaviors specific to the target activity. Specifically, Classroom A and C's DBR's had 4 appropriate carpet-time behaviors including, keep their hands and feet to themselves, actively participate in carpet time 
lessons, speak only when given permission (or when called on), and only manipulating objects related to the activity. Classroom B's C-DBR included the following five appropriate center-time behaviors; ask permission before leaving a center, walk in the classroom, use materials appropriately, use furniture appropriately, and keep their hands and feet to themselves. Each behavior listed on the DBR has a rating scale underneath that ranged from 1 (Never occurred) to 10 (Always occurred).

Behavior Intervention Rating Scale (BIRS)

The BIRS (Appendix D) was used to measure the social validity of the Mystery Student intervention. This questionnaire includes 24 items ranging from 1 (strongly disagree) to 6 (strongly agree). The items address the teacher's view on the intervention in terms of acceptability, effectiveness, and time of implementation (Elliott \& Treuting, 1991). Factor analysis by Elliot and Treuting (1991) identified three factors for the BIRS: Acceptability (63\% of variance), effectiveness ( $6 \%$ of variance), and time of effectiveness (4.3\% of variance). Furthermore, a coefficient alpha yielded an alpha level of .97 for the entire scale. Acceptability, effectiveness, and time subscales yielded alphas of .97, .92, .87, respectively (Von Brock \& Elliott, 1987). Teachers completed the BIRS at the conclusion of the study. Total scores were calculated for each teacher and higher scores indicate greater perceptions of social validity.

\section{Materials}

\section{MotivAider ${ }^{\circledR}$}

A MotivAider ${ }^{\circledR}$ is a discrete electronic device that resembles a beeper, can be clipped onto clothing (e.g. belt loop and waist band) and serves as a tactile prompt (3-s vibration). This device can be programmed to vibrate on an interval or fixed time 
schedule. The MotivAider® was set to vibrate on a fixed- interval schedule of 90 seconds. The MotivAider® was given to the assistant teachers who were instructed to look up at each Mystery Student when prompted and record whether the students were engaged in appropriate behavior (+) or disruptive behaviors (-) on a data sheet that was provided to them (Appendix E).

\section{Prize Box}

A colorful box filled with teacher-approved toys, accessories and trinkets were placed in each classroom. The prize boxes were decorated with stickers, drawn on question marks, and the title, "Mystery Student." When any Mystery Student met the performance criterion, they were allowed to access a tangible from the box following an intervention period.

\section{Name Bag}

A bag filled with the names of every child enrolled in the class was used during the implementation of the intervention. Two names were pulled each intervention day, however; in order to increase the likelihood that every child would have the opportunity to experience being a "Mystery Student" during the 5-day week, the teachers did not return the two names to the bag for the remainder of that week. However, this component was unknown to the students.

\section{Teacher Data Sheet}

In order for teachers to determine whether each Mystery Student could be revealed and allowed to receive a reward after the target activities, teacher assistants were given a data sheet (Appendix E) to record instances of AEB and DB for each of the two Mystery Students. Data sheets included the operational definitions for AEB and DB, a 
row of ten blanks for each interval, and a space to calculate the percentage of intervals in which AEB occurred.

\section{Dependent Measures and Data Collection Procedures}

The primary dependent variable in the present study was aggregate class-wide levels of disruptive behavior. The definitions of disruptive behavior were established and operationally defined in collaboration with classroom teachers during a brief interview following initial referral. For Classroom A and Classroom C, disruptive behaviors included, inappropriate vocalizations, playing with objects, out of area, and aggression. Inappropriate vocalizations were defined as talking without permission to other students or teacher, shouting out, singing, or making noises not related to an ongoing task demand. Playing with objects was defined as manipulating objects without teacher permission or playing with objects not associated with ongoing task demands. Out of area behavior was defined as the child having one or more body parts outside the designated carpet or standing up without teacher permission. Aggression was defined as making contact with another person's body in a hitting, kicking, pinching, or biting manner with hands, feet or mouth. Disruptive behavior for Classroom B included, out of area, running, aggression towards others or objects, and the inappropriate use of furniture. Out of area behavior was defined as being more than one foot outside of the designated activity center they were assigned to without permission. Running was defined as moving about the classroom at a pace, which is anything above a slow walk (e.g., running, skipping or jogging). Aggression towards others included making contact with another person's body in a hitting, kicking, pinching, or biting manner with hands, feet or mouth while aggression towards objects was defined as throwing, intentionally breaking, hitting 
together any toys or other task-related items together in a forceful and inappropriate manner. Finally, inappropriate use of furniture was defined as jumping over, on, or off of furniture, standing on top of furniture or sitting on top of furniture not for sitting.

In contrast, the secondary dependent variable, appropriately engaged behavior was defined as both active and passive engagement for all three classrooms. Active engagement was defined as being involved in or attending to (e.g. looking at or writing on) independent seatwork, teacher instruction, designated classroom activity center, and/or engaging in task related (and permissible) vocalizations with teachers and peers. Passive engagement was defined as, listening to the teacher, listening to peers, reading silently, or looking at any task-related (and permissible) materials related to instruction or an activity center.

Aggregate class-wide levels of DB and AEB were obtained by conducting systematic direct observations (SDO; Appendix F). Instances of AEB and DB were recorded using a momentary time sampling (MTS) method in order to obtain an accurate representation of aggregate classroom behavior (Radley, O’Handley, \& LaBrot, 2015). At the beginning of a 10 s interval, the observer observed one of six students in a predetermined order and indicated whether they were engaged in AEB or DB; while noting that it was possible to record the absence of either. The observer then observed the next student in the same manner. Observing the alternating students continued until the observation period was complete (Briesch. Hemphill, Volpe, \& Daniels, 2015). Percentage of intervals in which AEB and DB occurred was calculated and graphed separately following each observation. Observation durations were between 10 - 20 minutes depending on the length of the target activity (i.e., if carpet time lasted 15 
minutes, then the observation lasted 15 minutes). In addition to SDO, aggregate classwide AEB was measured with the C-DBR's following each observation period across phases. Teacher-rated AEB was reported as the percentage of points earned out of the total possible points the classroom could earn on the C-DBR (see Figure 2).

The primary researcher and graduate and/or undergraduate students, who had been previously trained to observe and code a variety of behaviors, conducted the behavior observations. The primary researcher trained all observers on the operational definitions and coding schemes included in this study, and all observers were required to demonstrate $90 \%$ agreement with the primary researcher prior to data collection. The minimum acceptable IOA level was 90\%; if an IOA score fell below 90\%, the observer was retrained via the methods described above before being used as an observer again. One observer was retrained twice. Observers sat in an unobtrusive location in the classroom while conducting observations and used a digital audio device to cue observation intervals. Data were collected during the same activity throughout all phases of the study (carpet-time for classroom A \& C and center-time for C).

\section{Design and Data Analysis}

To evaluate the effectiveness of Mystery Student on improving disruptive behavior, an A/B/A/B withdrawal design (Cooper et al., 2007) across three classrooms was utilized. A is the baseline phase/withdrawal phase, while B represents the intervention phases. Phase changes occurred based on the trend, level, and stability of the primary dependent variable: collapsed classroom disruptive behaviors. In addition to visual analysis of the data, the effect size Tau-U was calculated. Tau-U is a nonparametric effect size calculation for evaluating non-overlap data between two phases 
(Parker, Vannest, Davis, \& Sauber, 2011). Tau-U can test for a baseline trend in an undesired direction so the trend can be corrected for in the effect size calculation and thus, is considered a conservative analysis method (Parker et al., 2011). Effects sizes between 0 and 0.20 are considered small effects, 0.20 and 0.60 are moderate effects, 0.60 and 0.80 are large effects, and above 0.80 are very large effects (Vannest \& Ninci, 2015). In order to analyze the correspondence between the levels of AEB that were directly observed and levels that were measured by C-DBR's, a Pearson's correlation was calculated.

\section{Procedures}

\section{Screening}

During the screening observation, the researcher instructed teachers to continue to manage their classroom in their typical manner, utilizing any reinforcement and consequent procedures they normally used. In order for a classroom to screen into the study, disruptive behavior had to occur in at least $30 \%$ of intervals. Observation procedures were the same as those during all other phases of the study.

\section{Behavior Identification and DBR Training Meeting}

The primary researcher met with each teacher dyad in the afternoon (after children were dismissed) to identify and define the target behaviors (AEB \& DB). First, teachers identified specific disruptive behaviors that were occurring during the target activity. Next, teachers identified appropriate behaviors they would like to see their children engage in. After the teachers identified the specific AEBs and DBs, the primary researcher inserted the desired appropriate behaviors in a pre-formatted C-DBR and printed two copies for the lead teacher to use during the DBR training. 
Immediately following the behavior identification interview, the researcher trained the lead teacher on C-DBR procedures. First, the researcher explained what DBR's are and why they are useful (i.e., easy, quick, and measures teacher perception). Next, the researcher explained how the C-DBR's would measure the behaviors of the classroom as a whole. Then, teachers were instructed to rate their classroom's AEB during the target activity earlier that day for practice.

\section{Baseline}

During the baseline phase, teachers were instructed to implement their normal classroom management techniques during the target activity. Observers collected data during the time the target activity occurred. Data were used to determine the percentage of intervals in which problem behaviors and academic engagement occurred. Observers positioned themselves in an unobtrusive location in the classroom and did not interact with the children. The researcher and observers did not provide any feedback regarding behavior management and student performance.

\section{Teacher Training}

Prior to implementation of the "Mystery Student" independent group contingency, both teachers from each classroom met with the researcher for a training on the implementation procedures of the intervention. Teachers were given scripted instruction sheets that included 7 steps for implementation with examples of dialogues associated with each step (see Appendix G). The trainer then explained that each teacher would be responsible for one of two specific roles. Teachers were told that the responsibilities involved with the first role included; introduce and explain the Mystery Student intervention, provide frequent reminders regarding the ongoing intervention, and either; 
announce the Mystery Students, provide rewards, and provide examples of the appropriate behaviors that were demonstrated, or; announce that no Mystery Students can be revealed due to high instances of disruptive behavior. In contrast the responsibilities for the second role were to; wear the MotivAider ${ }^{\circledR}$, select the two Mystery Students from the bag, sequentially observe the selected Mystery Students' behaviors for three seconds each when prompted, record the behaviors of each student on the data sheet and inform the lead teacher whether the two students met the criteria to be revealed. All three lead teachers volunteered to undertake the first role, while the assistant teachers agreed to the responsibilities for the second role. The trainer then presented all of the materials relevant to the intervention to the teachers and explained and modeled their use. The procedural fidelity checklist in Appendix $\mathrm{H}$ lists out every training step.

\section{Mystery Student Intervention}

The teacher introduced the Mystery Student intervention to the class by telling them that they were going to play a game. Lead teachers stated the game parameters (i.e., intervention will be during carpet-time, names undisclosed) and described and demonstrated the behavior expectations. Teacher assistants' then selected two names from the bag, recorded them on the data sheet, and reminded the children that they could not know who the Mystery Students were and suggested that every child engage in appropriate behavior in case they are a Mystery Student for the day. The lead teacher then proceeded with scheduled classroom activity (e.g., carpet-time lesson or centertime). Lead teachers were trained to provide at least 2 verbal reminders regarding the ongoing Mystery Student intervention during the activity (e.g., "remember there are Mystery Students being watched"). 
During the intervention period, the assistant teachers were equipped with the MotivAider® that was set to prompt (e.g., vibrate) every 90 seconds, a clipboard and data sheet. Assistant teachers partook in the ongoing activity; however, when prompted, the teachers would look at one Mystery student and mark + for AEB, or - for DB on the data sheet then move on to the second Mystery Student and recorded their behavior.

Once the scheduled activity ended, teachers determined whether either Mystery Student could be revealed and rewarded. Mystery Students were revealed and rewarded if they exhibited AEB at least $60 \%$ of intervals observed by the teacher assistant. If the students met the criteria, the teacher revealed their identity, presented them with the prize box, and explained why the reward was given (e.g., "Suzy gets to pick a prize because she was a Mystery Student and kept her hands and feet to herself during carpet time") to the entire classroom. If the Mystery Students did not meet the criteria, teachers announced that the names of the Mystery Student could not be revealed because they were not behaving appropriately. There were incidents in which, one student met the criteria and the other did not. In these cases, teachers simply announced that only one name could be revealed because one was not behaving appropriately. The teachers then revealed and rewarded the student who met the criteria in the same manner as explained above.

\section{Withdrawal Phase}

Teachers were instructed to withhold the implementation of all Mystery Student intervention components during the withdrawal phase. Teachers were instructed to not mention the Mystery Student unless children asked. If children asked about the game, 
they were told that they weren't playing the game today. Data were collected in the same manner as the baseline and intervention phases using C-DBR's and direct observations.

\section{Interobserver Agreement}

Interobserver Agreement (IOA) was conducted for at least $40 \%$ of all behavior observations, in each condition, across each of the three classrooms. IOA was calculated with the exact agreement method (Cooper, et. al., 2007) in which, the total number of agreements between the two observers was divided by the sum of agreements and disagreements, which was then multiplied by 100 .

For classroom A, IOA was obtained for $77.27 \%$ of all observations with an average agreement of $92.94 \%$ (range $=87.78-100.00 \%$ ). IOA was gathered for $57.14 \%$ of baseline observations and agreement averaged $92.95 \%$ (range $=87.78-100.00 \%$ ). During the first treatment phase, IOA was calculated for $100 \%$ of the observations with an average agreement of $93.13 \%$ (range $=90.00-100.00 \%)$. IOA was calculated for $80 \%$ of the withdrawal observations, with an average agreement of $93.06 \%$ (range $=83.33$ $100.00 \%$ ). In the final intervention phase, $80 \%$ of observations were coded for IOA and had an average agreement of $92.60 \%$ (range $=90.00-93.93 \%$ ).

In Classroom B, IOA was obtained during $57.14 \%$ of all observations with an average agreement at $96.31 \%(91.67 \%-100 \%)$. IOA was gathered for $40 \%$ of baseline observations and agreement averaged $95.31 \%$ (range $=91.67-98.95 \%)$. During the first treatment phase, IOA was calculated for $60 \%$ of the observations with an average agreement of $96.13 \%$ (range $=91.67-100.00 \%$ ). IOA was calculated for $60 \%$ of the withdrawal observations, with an average agreement of $97.33 \%$ (range $=95.83$ - 
$97.22 \%$ ). In the final intervention phase, $80 \%$ of observations were coded for IOA and had an average agreement of $96.19 \%$ (range $=92.22-98.81 \%)$.

IOA was obtained during $57.14 \%$ of all observations in Classroom $\mathrm{C}$ and was found to have an agreement average of $94.15 \%(89.39 \%-97.22 \%)$. IOA was gathered for $57.14 \%$ of baseline observations and agreement averaged $93.29 \%$ (range $=91.67-$ 94.44\%). During the first treatment phase, IOA was calculated for $40 \%$ of the observations with an average agreement of $94.17 \%$ (range $=91.67-96.67 \%)$. IOA was calculated for $60 \%$ of the withdrawal observations, with an average agreement of $93.68 \%$ $($ range $=89.39-96.67 \%)$. In the final intervention phase, $50 \%$ of observations were coded for IOA and had an average agreement of $96.52 \%$ (range $=95.83-97.22 \%$ ).

\section{Procedural Integrity and Treatment Integrity}

$100 \%$ of the observations and trainings were coded for integrity by completing checklists (Appendices G-I). Procedural integrity was obtained for $100 \%$ of training sessions with $100 \%$ of the steps completed, across all teachers and training session. In other words, the trainer implemented $100 \%$ of the steps included in the DBR and intervention training sessions. IOA was collected during $100 \%$ of all training sessions with $100 \%$ agreement for all sessions.

During the intervention phases, the observers used a checklist to judge which aspects of the intervention the teacher implemented correctly (Appendix I). During the baseline and withdrawal phases, checklist items (Appendix J) were related to whether or not the observers sat in an unobtrusive location, teachers were instructed to not implement any component of the Mystery Student intervention, and that the teachers were not utilizing the intervention components. 
For Classroom A, observer ratings of procedural integrity indicated that $100 \%$ of the steps in baseline and withdrawal were met. Observer ratings indicated teachers utilized $96 \%$ of steps during the first intervention phase (range $=90-100 \%$ ), and $97.50 \%$ (range $=90-100 \%)$ of the steps during the second intervention phase. IOA was calculated during $47.61 \%$ of integrity observations and $100 \%$ agreement was obtained.

For Classroom B, observer ratings of integrity during baseline indicated 100\% of steps during baseline and withdrawal were met. Also, observer ratings of teacher integrity indicated teachers utilized $100 \%$ of the steps during the first and second intervention phases. IOA was calculated during $57.14 \%$ of integrity observations and $100 \%$ agreement was obtained.

For Classroom C, observer ratings of integrity during baseline indicated $100 \%$ of steps during the baseline and withdrawal phases were met. During the first intervention phase, teachers implemented an average of $98 \%$ of the intervention components during the first intervention phase (range $=90-100 \%$ ), and $94.72 \%$ of the intervention steps during the final intervention phase. IOA was calculated during $47.61 \%$ of integrity observations and $100 \%$ agreement was obtained. 


\section{CHAPTER III - RESULTS}

\section{Disruptive and Academically Engaged Behavior}

The percentages of intervals in which disruptive behavior (DB) and appropriately engaged behavior (AEB) were directly observed for each classroom are displayed in Figure 1. Tau-u effect sizes for each class are presented in Table 1. Teacher-reported levels of AEB were obtained via class-wide DBR's; the percentage of points earned daily were graphed and are displayed in Figure 2.

Table 1

AEB and DB from baseline to intervention (Tau-U Effect Sizes with 90\% CI)

\begin{tabular}{ccc}
\hline Classroom & Disruptive Behavior & Appropriately Engaged Behavior \\
\hline A & 1.00 & 0.97 \\
B & 0.98 & 0.76 \\
C & 0.97 & 0.92 \\
\hline
\end{tabular}

Tau-U effect size scores ranging from 0-.20 are considered small effects, scores ranging from .20-.60 are considered moderate effects, scores ranging from .60-.80 are considered large effects, and scores above .80 are considered a very large effect (Vannest \& Ninci, 2015).

Table 2

Average Levels of $A E B$

\begin{tabular}{ccccccccc}
\hline & \multicolumn{2}{c}{ Baseline } & \multicolumn{2}{c}{ Treatment 1 } & \multicolumn{2}{c}{ Withdrawal } & \multicolumn{2}{c}{ Treatment 2 } \\
\hline & DBR & Observed & DBR & Observed & DBR & Observed & DBR & Observed \\
\hline Classroom A & 46.8 & 47.44 & 62.5 & 73.63 & 48 & 46.71 & 59 & 72.86 \\
Classroom B & 39.6 & 55.22 & 60 & 82.61 & 50.8 & 66.12 & 62.8 & 66.12 \\
Classroom C & 54.28 & 62.83 & 66.73 & 84.98 & 61 & 58.20 & 65 & 88.38 \\
\hline
\end{tabular}

Mean Percentages of Points Earned on DBR's and Mean Levels of AEB Obtained Via Direct Observations 




Figure 1. Direct Observation Data

Percentage of intervals observed for students' appropriately engaged behavior (AEB) and student disruptive behavior (DB). 


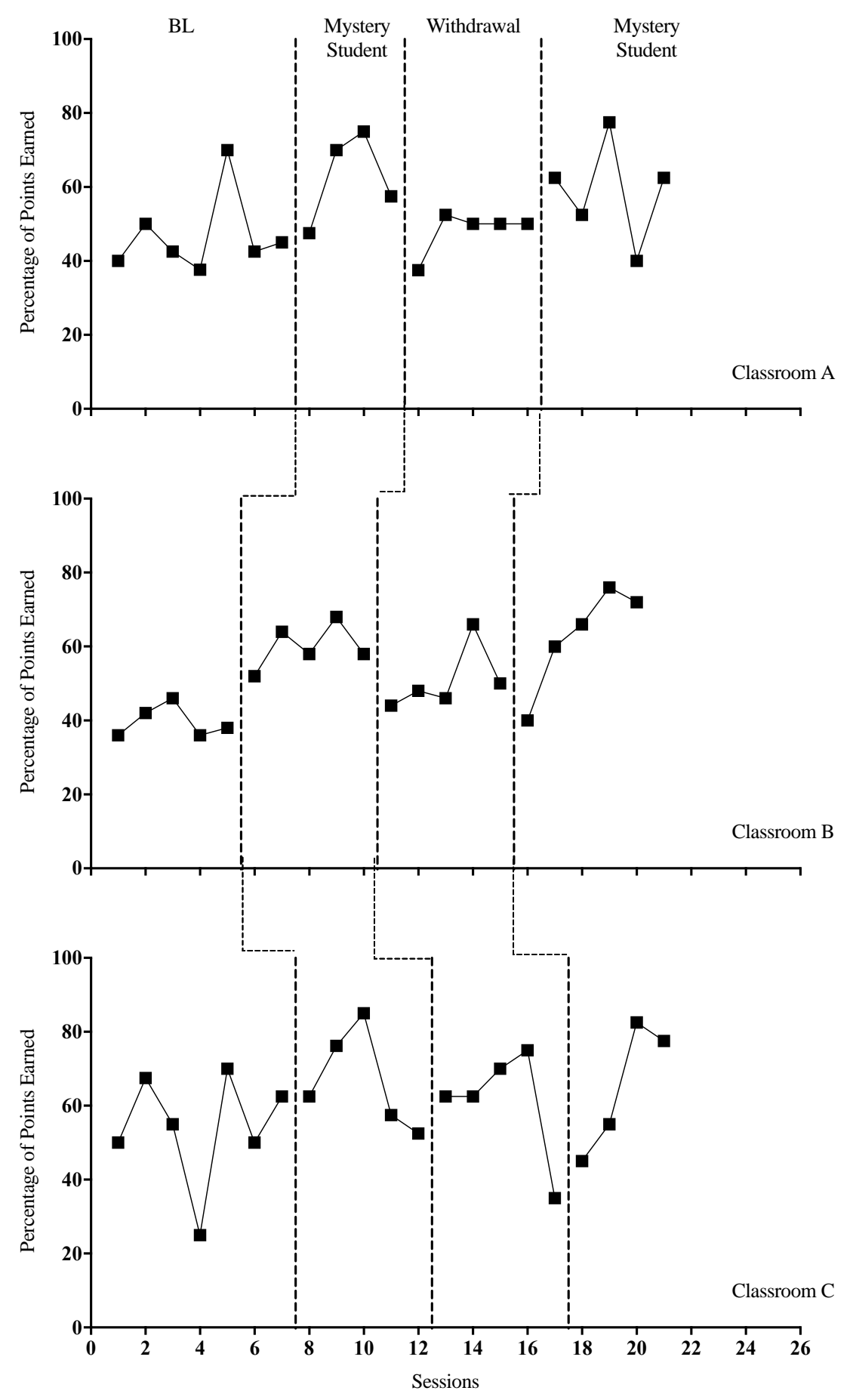

Figure 2. Teacher-Rated Class-wide Appropriately Engaged Behavior Daily percentage of points earned on DBR's for each participating classroom. 


\section{Classroom A}

During baseline, students in Classroom A (top panel) displayed DB during an average of $42.94 \%$ (range $=22.00 \%-55.90 \%$ ) intervals observed. DB data during this phase was variable. The students engaged in AEB during an average of $46.38 \%$ (range $=$ $39.00 \%-61.84 \%$ ) of observed intervals in baseline. Throughout this phase, AEB data was low and continued on a downward trend. Immediately following the implementation of the first intervention phase, a clear divergence between DB and AEB were observed. Specifically, levels of DB dropped low and continued on a stable decreasing trend, averaging $14.78 \%$ (range $=10.00 \%-17.85 \%$ ) across the phase. Furthermore, an immediate increase in AEB was observed following the second implementation of Mystery Student. Throughout the intervention implementation, levels of AEB remained high and stable with an average of $73.63 \%$ (range $=60.52 \%-78.20 \%$ ). The intervention was removed from the classroom for a short time during the withdrawal phase. An instant convergence between $\mathrm{BD}$ and $\mathrm{AEB}$ was observed during the withdrawal phase.

Specifically, an immediate increase in DB levels was observed and levels remained high, averaging $41.07 \%$ (range $=34.60 \%-48.33 \%$ ), while intervals containing appropriately engaged behavior remained lower, averaging $46.71 \%$ (range $=55.12 \%-38.46 \%$ ). Similar to the previous treatment phase, levels of DB and AEB diverged immediately after reimplementation of Mystery Student. Percentage of intervals containing disruptive behaviors immediately decreased to an average of $19.06 \%$ (range $=21 \%-35 \%$ ) and remained at stable low levels while levels of AEB were high and stable, averaging $72.56 \%($ range $=66.67 \%-81.67 \%)$. The Tau-U score suggests a very large effect size 
for both DB $($ Tau-U $=1.00 ; 90 \% \mathrm{CI}=0.57-1.00)$ and $\mathrm{AEB}(\mathrm{Tau}-\mathrm{U}=0.97 ; 90 \% \mathrm{CI}$ $=0.55-1.39)$ in Classroom A.

\section{Classroom B}

Prior to implementation of the Mystery Student intervention, levels of DB were stable and high, averaging $41.51 \%$ (range $=38.33 \%-46.67 \%$ ). Baseline levels of AEB were variable and averaged $46.38 \%$ (range $=39.00 \%-61.84 \%)$. An immediate diversion of between AEB and DB levels were observed following implementation of the Mystery Student intervention. Specifically, levels of DB immediately decreased and remained low with an average of $13.46 \%$ (range $=8.33 \%-21.43 \%$ ) while AEB levels increased to, and remained at, high levels. The withdrawal of the intervention resulted in a stable, increasing trend of DB levels, averaging $29.20 \%$ (range $=20.00 \%-39.40 \%$ ) and a stable decrease of AEB levels, averaging 66.12\% (range $=56.25 \%-73.80 \%$ ). When the intervention was reinstated for the second time, levels of DB and AEB were similar to those observed in the first intervention phase with DB averaging $14.30 \%$ (range $=$ $11.45 \%-14.30 \%)$ and AEB averaging $79.62 \%($ range $=65.56 \%-84.71 \%)$. The Tau-U score suggests a very large effect size for DB (Tau-U $=0.98 ; 90 \% \mathrm{CI}=0.54-1.41)$ and a large effect size for AEB (Tau-U $=0.76 ; 90 \% \mathrm{CI}=0.32-1.15)$ in Classroom B.

\section{Classroom C}

Before Mystery Student was implemented, children in classroom C engaged in high and variable levels of DB, averaging $32.77 \%$ (range $=18.33 \%-43.75 \%$ ), while levels of AEB were low and variable, averaging $62.83 \%$ (range $=48.33 \%-80.00 \%$ ). Low, stable levels of DB and high, stable levels of AEB were observed during the implementation of Mystery with DB averaging $11.14 \%$ (range $=5.00 \%-19.04 \%$ ) and 
AEB averaging $84.99 \%$ (range $=80.00 \%-93.33 \%)$. Withdrawal of the intervention led to an immediate increase in DB $(M=36.87 \%$; range $=33.33 \%-43.33 \%)$ with levels steadily increasing. Intervention removal also results in an immediate decrease in AEB $(M=58.20 \% ;$ range $=50.00 \%-64.58 \%)$ with levels decreasing throughout the phase. Reimplementation resulted in an immediate decrease in DB $(M=8.27 \%$; range $=5.00 \%$ $13.89 \%)$ and an increase in AEB $(M=88.38 \%$; range $=84.72 \%$ - 93.05\%). The Tau-U score suggests a very large effect size for both DB $($ Tau-U $=0.96 ; 90 \% \mathrm{CI}=0.52-1.41$ ) and AEB (Tau-U $=0.92 ; 90 \% \mathrm{CI}=0.48-1.36)$ in Classroom C.

\section{Teacher-Rated AEB}

Following the designated observation period, the primary teacher completed a CDBR to rate class-aggregate appropriate behavior for the target activity. The percentage of points earned daily, in each phase, are presented in Table 2 in conjunction with mean levels of AEB that were obtained via direct observations. Furthermore, a correlation between levels of AEB from C-DBR's and levels of AEB via direct observations was conducted so as to determine the extent to which teachers' perceptions of behavior change matched to that of direct observations. In total, results of the correlation suggest; there was a large, positive association between Teacher A1 and B1's ratings and levels of AEB that were directly observed ( $r=.60 \& r=.75$, respectively) and a medium, positive association between Teacher C's ratings and the directly observed levels of AEB ( $r=$ .39). In total, teachers' ratings were correlated with direct observations. These

correlations strengthen the validity of the direct observation data and demonstrate that the teachers' perceived similar behavior changes across conditions 


\section{Social Validity of Mystery Student}

All three lead teachers, and two assistant teachers, completed the BIRS so as to assess the acceptability of the Mystery Student intervention. Mean scores were 4.67, 5.46, and 5.33 for Teachers A1, B1, and C1, respectively. In total, primary teachers favored the use of the Mystery Student intervention on the factors of acceptability, effectiveness, and time. Table 3 includes mean scores across each factor, across teachers.

Table 3

BIRS Factor and Total Scores

\begin{tabular}{cccc}
\hline & Acceptability & Effectiveness & Time of Effectiveness \\
\hline Teacher A1 & 4.67 & 4.28 & 5.00 \\
Teacher A2 & 4.67 & 4.28 & 5.00 \\
Teacher B1 & 5.45 & 4.85 & 5.50 \\
Teacher B2 & 4.87 & 4.87 & 4.14 \\
Teacher C1 & 5.33 & 5.43 & 5.00 \\
\hline Total & 5 & 4.6 & 4.9 \\
\hline
\end{tabular}




\section{CHAPTER IV - DISCUSSION \\ Research Questions}

The increased focus on the early identification and intervention of preschool children has resulted in early intervention practices that have shown to be advantageous for improving social, emotional, and behavioral skill repertoires in young children (Raver et al., 2009; Webster-Stratton \& Herman, 2009; Webster-Stratton, et. al.,, 2004). However, the research on early intervention practices is generally limited to individualized treatment practices, which can be resource intensive and result in low teacher integrity (Litow \& Pumroy, 1975). An alternative approach at reducing disruptive behaviors in preschool settings may be the utilization of group contingencies. Although group contingencies may be effective, feasible classroom management strategies for preschool teachers to implement, only few studies exist on the use of group contingencies in preschool or Head Start classrooms (Brown, Reschly \& Sabers, 1974; Bushell, Wrobel, \& Michaelis. 1968; Hoag, 2007; Ling \& Barnett, 2013; Little et al., 2015; Maggin et al., 2012; Maus, 2006; Murphy, Theodore, Aloiso, Alric-Edwards, \& Hughes, 2007). Preliminary results of the current study provides additional support for the use of an independent group contingency to improve the behaviors in preschool classrooms

Question 1

The increased focus on the early identification and intervention of preschool children has resulted in early intervention practices that have shown to be advantageous for improving social, emotional, and behavioral skill repertoires in young children (Raver et al., 2009; Webster-Stratton \& Herman, 2009; Webster-Stratton, et. al.,, 2004). 
However, the research on early intervention practices is generally limited to individualized treatment practices, which can be resource intensive and result in low teacher integrity (Litow \& Pumroy, 1975). An alternative approach at reducing disruptive behaviors in preschool settings may be the utilization of group contingencies. Although group contingencies may be effective, feasible classroom management strategies for preschool teachers to implement, only few studies exist on the use of group contingencies in preschool or Head Start classrooms (Brown, Reschly \& Sabers, 1974; Bushell, Wrobel, \& Michaelis. 1968; Hoag, 2007; Ling \& Barnett, 2013; Little et al., 2015; Maggin et al., 2012; Maus, 2006; Murphy, Theodore, Aloiso, Alric-Edwards, \& Hughes, 2007). Preliminary results of the current study provides additional support for the use of an independent group contingency to improve the behaviors in preschool classrooms.

\section{Question 2}

An immediate increase in levels of appropriately engaged behaviors were observed when the Mystery Student intervention was implemented in all three classrooms. Furthermore, levels of appropriately engaged behavior remained stable and high during both intervention phases. In addition, large (Classroom B) and very large (classrooms A \& C) Tau-u effect sizes were calculated for differences in AEB from baseline to intervention further suggesting that the Mystery Student intervention was effective at increasing more appropriate behavior. Teachers gave their classrooms more points on the C-DBR's during both intervention phases then they did during the baseline and withdrawal phases, suggesting that they recognized an increase in appropriately 
engaged behaviors. These results are consistent with the findings of one study that applied an independent group continency with preschool children (Filcheck, 2004).

\section{Question 3}

The final question in this current study addressed the Head Start teachers' acceptability of the Mystery Student intervention. In order to assess the teachers' acceptability of the current intervention, each lead teacher and two teacher assistants, completed the BIRS (Elliot and Treuting, 1991) following the final intervention phase. Combined mean ratings for all teachers suggest the Mystery Student intervention was deemed acceptable (5), effective (4.6), and time efficient (4.9). This contributes to, and is consistent with, previous resaerch investigating group contingencies in preschool settings (Hoag, 2007; Hunt, 2013; Filcheck, 2004; Kohlet et. al., 1995; Ling \& Barnett, 2013; Maus, 2007; Murphy, et. al., 2007; Pasqua, Dart, Radley, 2016; Pokorski, et al., 2016; Swiezy, Matson, \& Box, 1992; Reitman Murphy, Hupp, \& O’Callaghan, 2004).

\section{Limitations and Future Directions}

Although both intervention conditions were found to generally result in positive changes in classwide behavior, results should be interpretated with caution due to the following limitations. First, internal validity may be diminished due to the multicomponent nature of the intervention. In other words, because the Mystery Student intervention was compromised of several components (antecedant manipulations, frequent reminders, positive reinforcement consequences, etc.) it is unknown what components, or combination of components, were directly responsible for the observed behavior changes. Future research should investigate the effectiveness of each component included in the Mystery Student intervention. 
Second, because this study was single-case in nature, the results cannot be generalized to other populations and settings until further research has investigated the effectiveness of the Mystery Student intervention in those settings and with those populations. This study should be conceptualized as a pilot of a novel intervention strategy to reduce the disruptive behavior in three Head Start classrooms. Although the intervention protocol can be adjusted to fit other ages and environments, equivalent results can not be assumed until the literature base is expanded.

Another limititation worth noting is the lack of interobserver agreement on the assistant teachers' observations of the two Mystery Students during the intervention phases. Having two observsers simultaneously completing the teacher data sheet would have required additional personnel which was not readily available. It is important to consider the possibility that the teachers' recording could have been inaccurate which could have resulted in disruptive behavior being advantagiously reinforced or appropriate behaviors not being reinforced. Future research on the Mystery Student intervention should attempt to measure the accuracy of teachers' observations of the target students.

A fourth limitation worth noting is in relation Classroom C's withdrawal of participation furing the second intervention phase. Teacher $\mathrm{C} 1$ was activly serving the military and due to a required training, she was not present during the fifth day of the second intervention phase. While researchers intended to implement the Mystery Student intervention with the additioanl support of the substitute teachers, Teacher C2 stated she did not what to implement the Mystery Student intervention for the remainder of the academic year without her former lead teacher and did not want to partake in any part of 
the research project because of the new and large amount of responsibilties she now held. Because teacher $\mathrm{C} 1$ dropped, serval things remain unknown including, her demographics, her teaching experience, and her acceptability of the Mystery Student intervention.

An additional limitation that deserves recognition is the lack of follow-up data to determine whether the intervention produces sustained behavior improvements across long periods of time and if the intervention proceudres were still being implemeted. While conducting typical work-related activities, the primary research followed-up with Teachers A1 and B1. Teacher A1 indicated that she occasionally (one to three times a week) implements Mystery Student when she intruduces a new lesson during carpet time. Furthermore, Teacher B1 reported using the Mystery Student intervention during carpet time, and ceased the implementation of it during center-time. Future research should examine the implementation of Mystery Student during multiple classroom activities and ontain maintainence and follow-up data to increase generalizability. It is also important to recognize that the researcher failed to implement a procedure to fade out the Mystery Student intervention. Future resaearchers should develop and investigate procedures to fade out the intervnetion.

Finally, although teachers found Mystery Student to be a socially valid intervention, the extent to which the children percieved the acceptability of the intervention is unknown. While anecdotal, the primary researcher observed the children enjoying ongoing intervention components and teachers reported their children asking to play the game during the withdrawal phase; however, no objective data were collected, 
thus, it cannot be concluded the children considered Mystery Student as a socially valid intervention.

\section{Implications and Considerations}

Currently, the research on group contingencies is limited in preschool settings. Despite the aforementioned limitations, this study indicates that implementing a novel independent group contingency with a randomized component is an effective method for reducing disruptive behavior in preschool classrooms. Therefore, school psychologists working in preschool settings may consider this intervention for classrooms in which there are several children engaging in problem behaviors. However, given the preliminary nature of these findings, if the intervention is implemented, treatment integrity and outcomes should be closely monitored to quickly assess the impact of the intervention.

These results increase the limited research base on the effectiveness of group contingencies in reducing disruptive behavior and increasing appropriate behaviors in preschool students (Pokorski et al., 2016). Even more, this research is the first known to investigate the effectiveness of a randomized target student component in an independent group contingency. Furthermore, the Mystery Student may be a viable option to incorporate within an early childhood education setting that utilizes a PW-PBIS system at either a Tier I or Tier II level. Moreover, results of the current study suggest preschool teachers find a unique independent group contingency method as an acceptable intervention in two different activity periods (e.g., carpet time \& center time). Finally, this is only the second study in which DBR's are used concurrently with SDO's for 
group-level behavior assessment (Riley-Tillman et al., 2009). Future research should seek to replicate these findings, as well as account for the limitations in this study. 


\title{
APPENDIX A - TEACHER CONSENT FORM
}

\author{
Teacher Consent Form \\ Title of Study: The Effects of an Independent Group Cantingency. "Mystery Student" on Disnuptive Behavior in a Preschool
} Cassraam

Study Site: P.R.V.O. In Forrest County, MS

Name of Researcher \& University affiliation: Jamie Pasqua, B.A.; The University of Southern Mississippi

Dear Teacher,

Hello, my name is Jamie Pasqu, and I am graduate stodent at University of Southern Mississippi in the School Psychology Doctoral Program. I am currently condacting my thesis, which will assess the effectiveness of a elassroom based behavioral intervention. This study is being conducted under the supervision of Dr. Brad Dufrease.

Your classrooen has been referred for inclusion in this study for elevated levels of class-wide disruptive behaviors. This intervention airs to reduce class-wide disr-ptive behavior and aid in classroom management procedures. Please consider the following when deciding if you will participate in this study:

Purpose:

As previously stated, the purpose of the stady is to assess the effectiveness of a class-wide intervention aimed at reducing classroom disr-ptive behavior. The intervention, Mystery Student, utilizes classroom management and reinforcement procedures to effect ehange in the classroom setting. Student's levels of academic engagement will also be measured as part of the study. At the end of the study, you will be asked to rate various components and answer qualitative questions about the effectiveness of the intervention.

Procedure:

If you agree to participate in the study, you will be asked to perform several tasks aimed to improve classroom managenent. Prior to implementation of the interventions, you will be required to complete separate consultation and training sessions with me. The consultation session will be conducted to better identify the problem behavioes occurring in your classroom and when they are occarring.

Following the consultation session, a series of screening observations will occur to verify that woes elassroom is qua iffed for inclusion in the study. During this period, you will be asked to continue to implement your nocmal classroom management procedures for dealing with problem behaviors. If your classroom does not qualify for participation in the study, more appropriate services will be provided to you and your classroon.

If your classroom does qualify for participation, you will be required to attend a training session with me to explain and practice the steps of each intervention. Upon displaying $100 \%$ of the steps successfully and being able to accurately describe each step, the intervention phase will begin.

The "Mystery Student" intervention is a teacher led elasstoom intervention. During the intervention, you will be reg-ired to take data on a target (i.e., Mystery ) student's behavior. Specifically, you will be equipoed with a small, discrete electronic device that resembles a beeper, called a SotixAider 2 , which serves as a tactile prompt. When prompted by the Motiudiderk, you will look at the target student for that day and wrive a + (Sor appropriate behavior) or 2 - (for disr-ptive behavioc) on a data sheet. At the end of the intervention period you will ese the data sheet to make a decision whether the student eamed a reward or not. The goal of the intervention is for all of the students to engage in lower levels of disraptive behaviors and higher levels of appropriate behaviors

Myself and/or another trained groduate stodent from the USM School Psychology program will conduct classroom observations multiple times a week. The observers will not interfere with you oc your class daring this time. The observers will be measuring levels of disruptive behavior, academically engaged behavior, and your integrity with the treatment protocol (you will be peovided with a checklist to aid you in implementation). You will be provided with feedback on the implementation as needed throughout the stady.

Benefits:

Agroeing to participate in this study may offer several benefits for you and your students. By participating in this study you will be trained on the implementation of a new intervention technique that can be used with other students. An additional benefit is the expected decrease in inappropriate behaviors and the increased appropriate behaviors by your stedents.

Risks:

There appear to be very few risks for either you or your students participating in this study. The greatest discomfort for you may be related to implementing a new procedure in the classroom. To reduce discomfort, I and/oe other trained graduate students will provide training, materials, and will be available to answer any questions you may have. Your students should not experience any discomfort from the implementation of the recommended intervention. 
Will this information be kept confidential?

Your name and behavior infocmation will be kept confidential. To protect wour,and the student's privacy, you will be assigned a number. This number will be placed on all paper work. At no time will ary paperwock cootain your name. Please note that these recoeds will be held by a state entity and therefore are subject to disclosure if required by law.

Who do I contact with research questions? If you should have amy questions about this rescarch project, please feel free to contact Jamie Pasqa, B.A. at 985-373-0643 or De. Brad $A$. Dufrege at 601-266-5256. If you have any questions togarding your rights as a research participant, please feel free to contact the USM Institutional Review Board at 601-255-5509.

What if I do not want to participate?

Please understand that your participation is voluntary, your refusal to participate will involve no penalty or loss of benefits to which you are otherwise entitled, and you may discontinue your participation at any time without penalty or loss of benefits.

What if I DO want to participate? If you world like to participate, please sign the bottoen of this sheet. You may kecp the second copy for your records.

Participant Signature

Investigator Signature
Date

Date 


\section{APPENDIX B - IRB APPROVAL LETTER}

\section{f \\ (1) TUE UNIVERSITY OF \\ IIIIII SOUTHERN MISSISSIPPI}

INSTITUTIONAL REVIEW BOARD

118 College Drive $\$ 5147$ | Hattiesburg, MS 39406-0001

Phone: 601.266 .5997 | Fax: 601.266 .4377 | www.usmeduresearch instiutiocal review.bousd

\section{NOTICE OF COMMITTEE ACTION}

The project has been reviewed by The University of Southern Mississippi Institutional Review Board in accordance with Federal Drug Administration regulations (21 CFR 26, 111), Department of Health and Human Services (45 CFR Part 46), and university guidelines to ensure adherence to the following criteria:

- The risks to subjects are minimized.

- The risks to subjects are reasonable in relation to the anticipated benefits.

- The selection of subjects is equitable.

- Informed consent is adequate and appropriately documented.

- Where appropriate, the research plan makes adequate provisions for monitoring the data collected to ensure the safety of the subjects.

- Where appropriate, there are adequate provisions to protect the privacy of subjects and to maintain the confidentiality of all data.

- Appropriate additional safeguards have been included to protect vulnerable subjects.

- Any unanticipated, serious, or continuing problems encountered regarding risks to subjects must. be reported immediately, but not later than 10 days following the event. This should be reported to the IRB Office via the "Adverse Effect Report Form".

- If approved, the maximum period of approval is limited to twelve months.

Projects that exceed this period must submit an application for renewal or continuation.

PROTOCOL NUMBER: 15090404

PROJECT TITLE: The Effects of an Independent Group Contingency: "Myster Student" on Disruptive Behavior in Preschool Classrooms

PROJECT TYPE: New Project

RESEARCHER(S): Jamie Pasqua

COLLEGE/DIVISION: College of Education and Psychology

DEPARTMENT: Psychology

FUNDING AGENCY/SPONSOR: N/A

IRB COMMITTEE ACTION: Expedited Review Approval

PERIOD OF APPROVAL: $10 / 13 / 2015$ to $10 / 12 / 2016$

Lawrence A. Hosman, Ph.D.

Institutional Review Board 


\section{APPENDIX C - CLASS-WIDE DAILY BEHAVIOR RATING}

Class-Wide Direct Behavior Rating Form

Completed by:

Date:

Target Activity:

Instructions: Rate the following behaviors of your class on a scale of 1-10 as a whole for the target activity.

1. The children kept their hands and feet to themselves.

Circle the degree to which the children engaged in the behavior.

\begin{tabular}{llllllllll}
\hline 1 & 2 & 3 & 4 & 5 & 6 & 7 & 8 & 9 & 10 \\
Never & & & & Occasionally & & & & Always
\end{tabular}

2. The children were actively involved in the carpet time activity.

Circle the degree to which the children engaged in the behavior.

\begin{tabular}{llllllllll}
\hline 1 & 2 & 3 & 4 & 5 & 6 & 7 & 8 & 9 & 10 \\
Never & & & & & Occasionally & & & & Always
\end{tabular}

3. The children waited to be called on or given permission by the teacher before talking. Circle the degree to which the children engaged in the behavior.

\begin{tabular}{llllllllll}
\hline 1 & 2 & 3 & 4 & 5 & 6 & 7 & 8 & 9 & 10 \\
Never & & & & & Occasionally & & & & Always
\end{tabular}

4. The children refrained from playing with objects unrelated to the ongoing activity during carpet time.

Circle the degree to which the children engaged in the behavior.

\begin{tabular}{llllllllll}
\hline 1 & 2 & 3 & 4 & 5 & 6 & 7 & 8 & 9 & 10 \\
Never & & & & & Occasionally & & & & Always
\end{tabular}




\section{APPENDIX D - BEHAVIOR INTERVENTION RATING SCALE}

\section{BEHAVIOR INTERVENTION RATING SCALE}

Please respond to each of the following statements thinking about the intervention you implemented (i.e., Mystery Student). Please then circle the number associated with your response. Be sure to answer all statements.

\begin{tabular}{|l|c|c|c|c|c|c|}
\hline & $\begin{array}{l}\text { Strongly } \\
\text { Disagree }\end{array}$ & Disagree & $\begin{array}{c}\text { Slightly } \\
\text { Disagree }\end{array}$ & $\begin{array}{l}\text { Slightly } \\
\text { Agree }\end{array}$ & Agree & $\begin{array}{c}\text { Strongly } \\
\text { Agree }\end{array}$ \\
\hline $\begin{array}{l}\text { This was an acceptable intervention } \\
\text { for the students' problem behavior(s). }\end{array}$ & 1 & 2 & 3 & 4 & 5 & 6 \\
\hline $\begin{array}{l}\text { Most teachers would find this } \\
\text { intervention appropriate for behavior } \\
\text { problems in addition to the one(s) } \\
\text { described. }\end{array}$ & 1 & 2 & 3 & 4 & 5 & 6 \\
\hline $\begin{array}{l}\text { The intervention proved effective in } \\
\text { changing the students' problem } \\
\text { behavior(s). }\end{array}$ & 1 & 2 & 3 & 4 & 5 & 6 \\
\hline $\begin{array}{l}\text { I would suggest the use of this } \\
\text { intervention to other teachers. }\end{array}$ & 1 & 2 & 3 & 4 & 5 & 6 \\
\hline $\begin{array}{l}\text { The students' behavior problem(s) } \\
\text { were severe enough to warrant use of } \\
\text { this intervention. }\end{array}$ & 1 & 2 & 3 & 4 & 5 & 6 \\
\hline $\begin{array}{l}\text { Most teachers would find this } \\
\text { intervention suitable for the behavior } \\
\text { problem(s) described. }\end{array}$ & 1 & 2 & 3 & 4 & 5 & 6 \\
\hline $\begin{array}{l}\text { I would be willing to use this in the } \\
\text { classroom setting again. }\end{array}$ & 1 & 2 & 3 & 4 & 5 & 6 \\
\hline $\begin{array}{l}\text { The intervention would not result in } \\
\text { negative side effects for students. }\end{array}$ & 1 & 2 & 3 & 4 & 5 & 6 \\
\hline $\begin{array}{l}\text { The intervention would be appropriate } \\
\text { intervention for a variety of students. }\end{array}$ & 1 & 2 & 3 & 4 & 5 & 6 \\
\hline $\begin{array}{l}\text { The intervention is consistent with } \\
\text { those I have used I have used in } \\
\text { classroom settings. }\end{array}$ & 1 & 2 & 3 & 4 & 5 & 6 \\
\hline $\begin{array}{l}\text { The intervention was a fair way to } \\
\text { handle the students' problem } \\
\text { behavior(s). }\end{array}$ & 1 & 2 & 3 & 4 & 5 & 6 \\
\hline $\begin{array}{l}\text { The intervention is reasonable for the } \\
\text { behavior problem(s) described. }\end{array}$ & 1 & 2 & 3 & 4 & 5 & 6 \\
\hline $\begin{array}{l}\text { I like the procedures used in the } \\
\text { intervention. }\end{array}$ & 1 & 2 & 3 & 4 & 5 & 6 \\
\hline
\end{tabular}




\begin{tabular}{|c|c|c|c|c|c|c|}
\hline $\begin{array}{l}\text { The intervention was a good way to } \\
\text { handle these students' behavior } \\
\text { problem(s). }\end{array}$ & 1 & 2 & 3 & 4 & 5 & 6 \\
\hline $\begin{array}{l}\text { Overall, the intervention was } \\
\text { beneficial for the students. }\end{array}$ & 1 & 2 & 3 & 4 & 5 & 6 \\
\hline $\begin{array}{l}\text { The intervention quickly improved the } \\
\text { students' behavior. }\end{array}$ & 1 & 2 & 3 & 4 & 5 & 6 \\
\hline $\begin{array}{l}\text { The intervention will produce a lasting } \\
\text { improvement in the students' } \\
\text { behavior. }\end{array}$ & 1 & 2 & 3 & 4 & 5 & 6 \\
\hline $\begin{array}{l}\text { The intervention improved the } \\
\text { students' behavior to the point that it } \\
\text { is not noticeably deviate from other } \\
\text { students' behavior. }\end{array}$ & 1 & 2 & 3 & 4 & 5 & 6 \\
\hline $\begin{array}{l}\text { Soon after using the intervention, the } \\
\text { teacher noticed a positive change in } \\
\text { the problem behavior. }\end{array}$ & 1 & 2 & 3 & 4 & 5 & 6 \\
\hline $\begin{array}{l}\text { The students' behavior will remain at } \\
\text { an improved level even after the } \\
\text { intervention is discontinued. }\end{array}$ & 1 & 2 & 3 & 4 & 5 & 6 \\
\hline $\begin{array}{l}\text { Using the intervention should not only } \\
\text { improve the students' behavior in the } \\
\text { classroom, but also in other settings } \\
\text { (e.g., other classrooms, home). }\end{array}$ & 1 & 2 & 3 & 4 & 5 & 6 \\
\hline $\begin{array}{l}\text { When comparing these students with } \\
\text { well-behaved peers before and after } \\
\text { the use of the intervention, the } \\
\text { students' and the peer's behaviors are } \\
\text { more alike after using the intervention. }\end{array}$ & 1 & 2 & 3 & 4 & 5 & 6 \\
\hline $\begin{array}{l}\text { The intervention produced enough } \\
\text { improvement in the students' behavior } \\
\text { so the behavior no longer is a problem } \\
\text { in the classroom. }\end{array}$ & 1 & 2 & 3 & 4 & 5 & 6 \\
\hline $\begin{array}{l}\text { Other behaviors related to the problem } \\
\text { behavior(s) were also improved by the } \\
\text { intervention. }\end{array}$ & 1 & 2 & 3 & 4 & 5 & 6 \\
\hline
\end{tabular}

Adapted from Elliott, S., \& Von Brock Ireutipg, M. (1991). The behavior intervention rating scale: Development and validation of a pretreatment 


\section{APPENDIX E - TEACHER DATA SHEET}

Completed by:

Date:

Target Activityis

Instructions: When prompted by the MotiyAider every 1.5 minutes, look up at the Mystery Students and mark a + (for appropriate behavior) or a - (for disruptive behavior).

Mystery Student $1:$

\begin{tabular}{|l|l|l|l|l|l|l|l|l|l|}
\hline 1 & 2 & 3 & 4 & 5 & 6 & 7 & 8 & 9 & 10 \\
\hline & & & & & & & & & \\
& & & & & & & & & \\
\hline
\end{tabular}

Mystery Student 2:

\begin{tabular}{|l|l|l|l|l|l|l|l|l|l|}
\hline 1 & 2 & 3 & 4 & 5 & 6 & 7 & 8 & 9 & 10 \\
\hline & & & & & & & & & \\
\hline
\end{tabular}

\section{Disruptive Behaviors}

- Off-task behavior: student's attention is directed away the assignment or instructing teacher

- Out-of-area: the student has one or more body parts off of the designated rug or is standing up without teacher permission

- Inappropriate vocalizations: verbalization made without teacher permission such as speaking, yeling. humming, singing, and/or whispering

- Aggression: making contact with another person's body in a hitting, kicking, pinching, or biting manner with hands, feet or mouth.

- Playing with Objects: Manipulating any object without teacher permission or that is not related to the task.

\section{Appropriately Engaged}

- Active Engagement: student is involved in or attending to (e.g. looking at or writing on) independent seatwork/carpet time, teacher instruction, designated classroom activities, and/or engaging in task related (permissible) vocalizations with teachers and/or peers.

- Passive Engagement (e.g., listening to the teacher, reading silently, looking at instructional materials). 
OBSERVATION SHEET

\begin{tabular}{|c|c|c|c|c|c|c|c|c|c|c|c|c|}
\hline \multicolumn{3}{|c|}{ Teacher name: } & & \multicolumn{8}{|c|}{ Obse } & \multirow[b]{2}{*}{2.6} \\
\hline Interval & 1.1 & 1.2 & 13 & $\overline{1.4}$ & 1.5 & 1.6 & 2.1 & 2.2 & 2.3 & 2.4 & 2.5 & \\
\hline & $\mathrm{AEB}$ & $\mathrm{AEB}$ & AEB & AEB & $\mathrm{AEB}$ & $\mathrm{AEB}$ & $\mathrm{AEB}$ & AEB & $\mathrm{AEB}$ & $\mathrm{AEB}$ & AEB & $\mathrm{AEB}$ \\
\hline & DB & $\mathrm{DB}$ & $\mathrm{DB}$ & $\overline{\mathrm{DB}}$ & $\mathrm{DB}$ & DB & DB & DB & DB & $\mathrm{DB}$ & DB & DB \\
\hline \multirow[t]{3}{*}{ Interval } & 3.1 & 3.2 & 3,3 & 3.4 & 3.5 & 3.6 & 4.1 & 4.2 & 4.3 & 4.4 & 4.5 & 4.6 \\
\hline & AEB & $\mathrm{AEB}$ & AEB & $\mathrm{AEB}$ & AEB & AEB & $\mathrm{AEB}$ & AEB & $\mathrm{AEB}$ & $\mathrm{AEB}$ & $\mathrm{AEB}$ & $\mathrm{AEB}$ \\
\hline & DB & $\mathrm{DB}$ & $\mathrm{DB}$ & $\mathrm{DB}$ & $\mathrm{DB}$ & $\mathrm{DB}$ & $\mathrm{DB}$ & DB & DB & $\mathrm{DB}$ & $\mathrm{DB}$ & DB \\
\hline \multirow[t]{3}{*}{ Interval } & 5.1 & 5.2 & 5.3 & 5.4 & 5.5 & 5.6 & 6.1 & 6.2 & 6.3 & 6.4 & 6.5 & 6.6 \\
\hline & AEB & $\mathrm{AEB}$ & AEB & AEB & $\mathrm{AEB}$ & AEB & AEB & AEB & $\mathrm{AEB}$ & AEB & $\mathrm{AEB}$ & $\mathrm{AEB}$ \\
\hline & $\mathrm{DB}$ & $\mathrm{DB}$ & $\mathrm{DB}$ & $\mathrm{DB}$ & $\mathrm{DB}$ & $\mathrm{DB}$ & $\mathrm{DB}$ & $\mathrm{DB}$ & $\mathrm{DB}$ & $\mathrm{DB}$ & $\mathrm{DB}$ & $\mathrm{DB}$ \\
\hline \multirow[t]{3}{*}{ Interxal } & 2.1 & 72 & 73 & 7.4 & 7.3 & 76 & 8.1 & 8.2 & 8.3 & 8.4 & 8.5 & 8.6 \\
\hline & AEB & AEB & $\mathrm{AEB}$ & AEB & AEB & AEB & $\mathrm{AEB}$ & AEB & AEB & $\mathrm{AEB}$ & AEB & $\mathrm{AEB}$ \\
\hline & DB & $\mathrm{DB}$ & DB & $\overline{\mathrm{DB}}$ & DB & DB & $\mathrm{DB}$ & DB & DB & $\mathrm{DB}$ & DB & DB \\
\hline \multirow[t]{3}{*}{ Interval } & 9.1 & 9.2 & 93 & 9.4 & 9.5 & 9.6 & 10.1 & 10.2 & 10.3 & 10.4 & 10.5 & 10.6 \\
\hline & AEB & $\mathrm{AEB}$ & AEB & $\mathrm{AEB}$ & AEB & $\mathrm{AEB}$ & $\mathrm{AEB}$ & $\mathrm{AEB}$ & AEB & $\mathrm{AEB}$ & $\mathrm{AEB}$ & $\mathrm{AEB}$ \\
\hline & DB & $\overline{D B}$ & $\overline{\mathrm{DB}}$ & $\mathrm{DB}$ & DB & DB & DB & DB & DB & $\mathrm{DB}$ & DB & DB \\
\hline \multirow[t]{3}{*}{ Interval } & 11.1 & 11.2 & 11.3 & 11.4 & 11.5 & 11.6 & 12.1 & 12.2 & 12.3 & 12.4 & 12.5 & 12.6 \\
\hline & $\mathrm{AEB}$ & $\mathrm{AEB}$ & AEB & $\mathrm{AEB}$ & $\mathrm{AEB}$ & $\mathrm{AEB}$ & $\mathrm{AEB}$ & $\mathrm{AEB}$ & $\mathrm{AEB}$ & $\mathrm{AEB}$ & $\mathrm{AEB}$ & $\mathrm{AEB}$ \\
\hline & $\mathrm{DB}$ & $\mathrm{DB}$ & $\mathrm{DB}$ & $\mathrm{DB}$ & $\mathrm{DB}$ & $\mathrm{DB}$ & $\mathrm{DB}$ & $\mathrm{DB}$ & $\mathrm{DB}$ & $\mathrm{DB}$ & $\mathrm{DB}$ & $\mathrm{DB}$ \\
\hline \multirow[t]{3}{*}{ Interval } & 13.1 & 13.2 & 13.3 & 13.4 & 135 & 13.6 & 14.1 & 14.2 & 14.3 & 14.4 & 14.5 & 14.6. \\
\hline & AEB & AEB & $\mathrm{AEB}$ & AEB & AEB & AEB & AEB & $\widehat{A E B}$ & $\mathrm{AEB}$ & AEB & AEB & $\mathrm{AEB}$ \\
\hline & $\mathrm{DB}$ & $\mathrm{DB}$ & $\mathrm{DB}$ & $\mathrm{DB}$ & $\mathrm{DB}$ & $\mathrm{DB}$ & DB & $\mathrm{DB}$ & $\mathrm{DB}$ & $\mathrm{DB}$ & $\mathrm{DB}$ & $\mathrm{DB}$ \\
\hline \multirow[t]{3}{*}{ Inferval } & 15.1 & 15.2 & 15,3 & 15.4 & 15.5 & 15.6 & 16.1 & 16.2 & 16,3 & 16.4 & 16.5 & 16.6 \\
\hline & AEB & $\mathrm{AEB}$ & AEB & $\mathrm{AEB}$ & AEB & $\mathrm{AEB}$ & AEB & AEB & AEB & $\mathrm{AEB}$ & AEB & $\mathrm{AEB}$ \\
\hline & $\mathrm{DB}$ & $\mathrm{DB}$ & $\mathrm{DB}$ & $\mathrm{DB}$ & $\mathrm{DB}$ & $\mathrm{DB}$ & $\mathrm{DB}$ & $\mathrm{DB}$ & $\mathrm{DB}$ & $\mathrm{DB}$ & DB & DB \\
\hline \multirow[t]{3}{*}{ Interval } & 17.1 & 17.2 & 17.3 & 17.4 & 17.5 & 17.6 & 18.1 & 18.2 & 18.3 & 18.4 & 18.5 & 18.6 \\
\hline & $\mathrm{AEB}$ & $\mathrm{AEB}$ & AEB & $\mathrm{AEB}$ & $\mathrm{AEB}$ & $\mathrm{AEB}$ & $\mathrm{AEB}$ & $\mathrm{AEB}$ & $\mathrm{AEB}$ & $\mathrm{AEB}$ & $\mathrm{AEB}$ & $\mathrm{AEB}$ \\
\hline & $\mathrm{DB}$ & $\mathrm{DB}$ & $\mathrm{DB}$ & $\mathrm{DB}$ & $\mathrm{DB}$ & $\mathrm{DB}$ & $\mathrm{DB}$ & $\mathrm{DB}$ & $\mathrm{DB}$ & $\mathrm{DB}$ & DB & DB \\
\hline \multirow[t]{3}{*}{ Interval } & 19.1 & 19.2 & 19.3 & 19.4 & 19.5 & 19.6 & 20.1 & 20.2 & 20.3 & 20.4 & 20.5 & 20.6 \\
\hline & $\mathrm{AEB}$ & $\mathrm{AEB}$ & $\mathrm{AEB}$ & $\mathrm{AEB}$ & $\mathrm{AEB}$ & AEB & $\mathrm{AEB}$ & $\mathrm{AEB}$ & $\mathrm{AEB}$ & $\mathrm{AEB}$ & $\mathrm{AEB}$ & $\mathrm{AEB}$ \\
\hline & $\mathrm{DB}$ & DB & $\overline{\mathrm{DB}}$ & $\overline{\mathrm{DB}}$ & DB & $\overline{\mathrm{DB}}$ & $\mathrm{DB}$ & DB & DB & DB & $\mathrm{DB}$ & $\mathrm{DB}$ \\
\hline
\end{tabular}



Disruptive Behaviors

- Out-of-area: the student has one or more body parts off of the designated rug or is standing up without teacher permission

- Inappropriate vocalizations: verbalization made without teacher permission such as speaking, yelling, humming, singing, and/or whispering

- Aggression: making contact with another person's body in a hitting, kicking, pinching, or biting manner with hands, feet or mouth.

- Playing with Objects: Manipulating any object without teacher permission or that is not related to the task.

Appropriately Engaged

- Active Engagement: student is involved in or attending to (c.g. looking at or writing on) independent seatwork/carpet time, teache instruction, designated classroom activities, and/or engaging in task related (permissible) vocalizations with teachers and/or peers.

- Passive Engagement (e.g., listening to the teacher, reading silently, looking at instructional materials).

IOA: 


\section{APPENDIX G - PROCEDURAL INTEGRITY CHECKLIST FOR TEACHER DBR TRAINING}

Teacher Name:

Date: Observer:

\begin{tabular}{|c|c|}
\hline \multicolumn{2}{|l|}{ Procedural Integrity Steps } \\
\hline The trainer explains what DBR is and why it is useful. & $\checkmark \quad X \quad N / A$ \\
\hline The trainer reviews the steps for completing the DBR form with the teacher. & $\checkmark \times \quad$ N/A \\
\hline The trainer explains the operational definitions of the target behaviors. & $\checkmark \quad X \quad N / A$ \\
\hline Steps completed & / \\
\hline Percentage of Steps completed & \\
\hline
\end{tabular}




\section{APPENDIX H - SCRIPTED INSTRUCTION SHEET FOR MYSTERY STUDENT IMPLEMENTATION}

1) Introciuction of the "Mystery Student" Game

"Alright class, today we are going to play a game! The game is called, Mystery Student. This is how it works; everyone's name is in my special bag and I am going to pick two names out of this bag. The two names I pick will be my Mystery Students! Anyone of you can be a Mystery Student, however, I can't tell you who the Mystery Students are. "

2) State game parameter and describe and demonstrate behavioral expectations.

- "Both Mystery Stucents' behaviors will be closely watched closely during (activity) to make sure they (EXPLAIN \& DEMONSTRATE BEHAVIORS).

3) Explain reward procedures.

- "Both of my Mystery Students will have a chance to pick a reward from the prize box but only if they follow those rulesiexpectations."

4) Throughout the intervention phase, freçuently (2-4 times) remind the class of the angoing game.

- "Remember class, I still have two Mystery Students who are being watched for good behavior."

5) End the game and inform the children that it is time to reveal the Mystery Students.

- "Okay class it is time to reveal the Mystery Student."

6) If criterion is met, reveal Mystery Student(s), give them reward(s), and announce the tomorrow's game.

- "Great jab ___ and _____ you (both) get to pick a prize because you were the Mystery Students and you both exhibited good behavior like, (give behavior examples)"

- "Tomonow, everyone will have another chance at being a Mystery Student but remember, everyone should try their best to follow the expectations."

7) If criterion not met, do not reveal Mystery Student(s), explain why reward cannot be given and remind class they will have a chance tomorrow.

- "Sorry class, 1 can't tell you: (1) who the Mystery Students are because they were not observed to (explain target behaviors). (2) Who the other Mystery Student because they were not abserved to (explain target behaviors)."

- "Tomorrow, everyone will bave another chance at being a Mystery Student but remember, everyone should try their best to follow the expectations" 


\section{APPENDIX I - PROCEDURAL INTEGRITY CHECKLIST FOR TEACHER INTERVENTION TRAINING \\ Teacher Sanos: Date: \\ Phase: Observer:}

\begin{tabular}{|c|c|c|}
\hline \multicolumn{3}{|l|}{ Procedural Integrity Steps } \\
\hline The trainer explains the two different roles of teacher involvement & $Y$ & $\mathrm{~N}$ \\
\hline The trainer reviews the teacher script with the teachers & $\mathrm{Y}$ & $\mathrm{N}$ \\
\hline $\begin{array}{l}\text { The trainer presents and explains the materials needed for intervention implementation } \\
\text { including } \\
\text { - Prize Box } \\
\text { - MotivAiderß } \\
\text { - Bata Sheet } \\
\end{array}$ & $\mathrm{Y}$ & $\mathrm{N}$ \\
\hline The trainer explains the operational definitions of AEB. & $Y$ & $\mathrm{~N}$ \\
\hline The trainer explains and demonstrates how to use the MotivAider $B$ & $\mathrm{Y}$ & $\mathrm{N}$ \\
\hline The trainer explains and demonstrates how to complete the data sheet. & $Y$ & $\mathrm{~N}$ \\
\hline The trainer models the intervention script for the teachers & $\mathrm{Y}$ & $\mathrm{N}$ \\
\hline $\begin{array}{l}\text { The teacher role-plays the intervention with the trainer, allowing the teacher to practice } \\
\text { implementing the steps of the game. }\end{array}$ & Y & $\mathrm{N}$ \\
\hline $\begin{array}{l}\text { The trainer provides appropriate feedback contingent upon teachers' mistakes during the } \\
\text { role-play implementation session. }\end{array}$ & $\mathrm{Y}$ & $\mathrm{N}$ \\
\hline The trainer insures the teachers have a full understanding of the intervention components. & $Y$ & $\mathrm{~N}$ \\
\hline Steps completed & / & \\
\hline Percentage of Steps completed & & \\
\hline
\end{tabular}




\section{APPENDIX J - TREATMENT INTEGRITY CHECKLIST}

Teacher Name: Date: Observer:

\begin{tabular}{|c|c|}
\hline \multicolumn{2}{|l|}{ Intervention Steps } \\
\hline 1. Motivaidere device is turned on and programmed to vibrate on a fixed interval. & $\checkmark \times N / A$ \\
\hline 2. Teacher introduces the game and randomly selects names out of bag. & $\checkmark \times \mathrm{X} / \mathrm{A}$ \\
\hline 3. Game rules are explained and behavioral expectations are described and modeled. & $\sqrt{ } \mathrm{X} N / \mathrm{A}$ \\
\hline 4. Teacher frequently (2-5 times) reminds class of the ongoing game. & $\sqrt{ } \mathrm{X} \mathrm{N} / \mathrm{A}$ \\
\hline 5. Teacher completes the data collection sheet provided by the researcher. & $\checkmark \times \mathrm{N} / \mathrm{A}$ \\
\hline $\begin{array}{l}\text { 6. Teacher announces when the game is over and makes reward decision with } \\
\text { assistant teacher. }\end{array}$ & $\checkmark \times N / A$ \\
\hline $\begin{array}{l}\text { 7. If criterion is met, reveals Mystery Student(s), and explains reasons why the } \\
\text { Mystery Student(s) earned reward. }\end{array}$ & $\sqrt{ } \mathrm{X}$ N/A \\
\hline 8. If criterion is met, provides reward(s). & $\sqrt{ } \mathrm{X} N / \mathrm{A}$ \\
\hline $\begin{array}{l}\text { 9. If criterion not met, does not reveal Mystery Student(s), and explains why reward } \\
\text { cannot be given. }\end{array}$ & $\sqrt{ } \times \mathrm{N} / \mathrm{A}$ \\
\hline 10. Reminds class of tomorrow's game. & $\checkmark \times \mathrm{N} / \mathrm{A}$ \\
\hline 11. Teacher completes DBR. & $\checkmark \times \mathrm{X} / \mathrm{A}$ \\
\hline Steps completed & / \\
\hline \multicolumn{2}{|l|}{ Percentage of Steps completed } \\
\hline Teacher Require Retraining? & $\mathrm{Y}$ \\
\hline
\end{tabular}




\section{APPENDIX K - PROCEDURAL INTEGRITY CHECKLIST FOR BASELINE AND WITHDRAWAL PHASES \\ Teacher Daxein \\ Date: Observer:}

$\pm$

\begin{tabular}{|c|c|}
\hline \multicolumn{2}{|l|}{ Procedural Integrity Steps } \\
\hline The observer sits in an unobtrusive location in the classroom. & $\checkmark \times N / A$ \\
\hline $\begin{array}{l}\text { The observer reminds teacher to use typical behavior management strategies and to } \\
\text { not implement any components of the intervention. }\end{array}$ & $\checkmark \mathrm{X} N / \mathrm{A}$ \\
\hline The observer does not provide any feedback to teachers. & $\checkmark \times \quad N / A$ \\
\hline Steps completed & / \\
\hline Percentage of Steps completed & \\
\hline
\end{tabular}




\section{REFERENCES}

Albers, A. E., \& Greer, R. D. (1991). Is the three-term contingency trial a predictor of effective instruction? Journal of Behavioral Education, 1, 337-354.

Beeson, P. M., \& Robey, R. R. (2006). Evaluating single-subject treatment research: Lessons learned from the aphasia literature. Neuropsychology Review, 16, 161169.

Benedict, E., Horner, R. H., \& Squires, J. (2007). Assessment and implementation of positive behavior support in preschools. Topics in Early Childhood Special Education, 27, 174-192.

Blair, K. C., Fox, L., \& Lentini, R. (2010). Use of positive behavior support to address the challenging behavior of young children within a community early childhood program. Topics in Early Childhood Special Education, 30, 68-79.

Briesch, A. M., Chafouleas, S. M., \& Riley-Tillman, T. C. (2010). Generalizability and Dependability of Behavior Assessment Methods to Estimate Academic Engagement: A Comparison of Systematic Direct Observation and Direct Behavior Rating. School Psychology Review, 39(3), 408-421.

Briesch, A. M., Hemphill, E. M., Volpe, R. J., \& Daniels, B. (2015). An evaluation of observational methods for measuring response to classwide intervention. School Psychology Quarterly, 30(1), 37-49.

Brown, D., Reschly, D., \& Sabers, D. (1974). Using group contingencies with punishment and positive reinforcement to modify aggressive behaviors in a head start classroom. The Psychological Record, 24, 491-496. 
Bruns, D. A., \& Mogharreban, C. C. (2007). The gap between beliefs and practices: Early childhood practitioners' perceptions about inclusion. Journal of Research in Childhood Education, 21, 229.

Buscemi, L., Bennett, T., Thomas, D., \& Deluci, D. A. (1995). Head Start: Challenges and training needs. Journal of Early Intervention, 20, 1-13.

Bushell, D., Wrobel, P. A., \& Michaelis, M. L. (1968), Applying “Group” Contingencies To The Classroom Study Behavior Of Preschool Children. Journal of Applied Behavior Analysis, 1, 55-61.

Busk, P. L., \& Serlin, R. (1992). Meta-analysis for single case research. In T. R. Kratochwill \& J. R. Levin (Eds.). Single case research design and analysis: New Directions for Psychology and Education (pp. 187-212). Hillsdale, NJ: Lawrence Erlbaum.

Campbell, S. B. (1990). Behavior problems in preschool children: Clinical and development issues. New York, NY: Guilford Press.

Campbell, S. B. (1995). Behavior problems in preschool children: A review of recent research. Journal of Child Psychology and Psychiatry, 36, 113-149.

Campbell, S. B., Shaw, D. S., \& Gilliom, M. (2000). Early externalizing behavior problems: Toddlers and preschoolers at risk for later maladjustment. Development and Psychopathology, 12(3), 467-488.

Chafouleas, S. M., Christ, T. J., Riley-Tillman, T. C., Briesch, A. M., \& Chanese, J. M. (2007). Generalizability and Dependability of Direct Behavior Ratings to Assess Social Behavior of Preschoolers. School Psychology Review, 36(1), 63-79. 
Chafouleas, S. M., Kilgus, S. P., \& Hernadez, P. (2009). Using Direct Behavior Rating (DBR) to screen for school social risk: A preliminary comparison of methods in a kindergarten sample. Assessment for Effective Intervention, 34, 214-223.

Chafouleas, S. M., McDougal, J. L., Riley-Tillman, T. C., Panahon, C. J., \& Hilt, A. M. (2005). What do daily behavior report cards (DBRCs) measure? An initial comparison of DBRCs with direct observation for off-task behavior. Psychology in the Schools, 42(6), 669-676.

Chafouleas, S. M., Riley-Tillman, T. C., \& Christ, T. J. (2009). Conceptual Foundation for DBR. Assessment for Effective Intervention, 195-200.

Chafouleas, S. M., Riley-Tillman, T. C., \& McDougal, J. L. (2002). Good, bad, or inbetween: How does the daily behavior report card rate? Psychology in the Schools, 39(2), 157-169.

Chafouleas, S. M., Riley-Tillman, T. C., \& Sassu, K. A. (2006). Acceptability and Reported Use of Daily Behavior Report Cards among Teachers. Journal of Positive Behavior Interventions, 8(3), 174-182.

Chafouleas, S. M., Sanetti, L. M. H., Kilgus, S. P., \& Maggin, D. (2012). Evaluating sensitivity to behavioral change across consultation cases using Direct Behavior Rating Single-Item Scales (DBR-SIS). Exceptional Children, 78, 491-505.

Christ, T. J., Riley-Tillman, T. C., \& Chafouleas, S. M. (2009). Foundation for the development and use of direct behavior rating (DBR) to assess and evaluate student behavior. Assessment for Effective Intervention, 34(4), 201-213. 
Conroy, M. A., Dunlap, G., Clarke, S., \& Alter, P. J. (2005). A descriptive analysis of behavioral intervention research with young children with challenging behavior. Topics in Early Childhood Special Education, 25, 157-166.

Conroy, M. A., Sutherland, K. S., Snyder, A. L., \& Marsh, S. (2008). Classwide interventions effective instruction makes a difference. Teaching Exceptional Children, 40(6), 24-30.

Cooper, J. O., Heron, T. J., \& Heward, W. L. (2007). Applied Behavior Analysis (2nd ed.). Boston, MA: Pearson.

Dufrene, B. A., Doggett, R. A., Henington, C., \& Watson, T. S. (2007). Functional assessment and intervention for disruptive classroom behaviors in preschool and Head Start classrooms. Journal of Behavioral Education, 16, 368-388.

Dunlap, G., \& Fox, L. (2011). Function-based interventions for children with challenging behavior. Journal of Early Intervention, 33, 333-343.

Dunlap, G., Strain, P., \& Fox, L. (2006). Prevention and Intervention with Young Children's Challenging Behavior: Perspectives Regarding Current Knowledge. Behavioral Disorders, 32(1), 29-45.

Egger, H. L., \& Angold, A. (2006). Common emotional and behavioral disorders in preschool children: presentation, nosology, and epidemiology. Journal of Child Psychology and Psychiatry, and Allied Disciplines, 47(3-4), 313-37.

Elliott, S., \& Von Brock-Treuting, M. (1991). The behavior intervention rating scale: Development and validation of a pretreatment acceptability and effectiveness measure. Journal of School Psychology, 29, 43-51. 
Entwisle, D. (1995). The Role of Schools in Sustaining Early Childhood Program Benefits. The Future of Children, 5(3), 133-144.

Fallon, L. M., O’Keeffe, B. V., Gage, N. A., \& Sugai, G. (2015). Brief report: Assessing attitudes toward culturally and contextually relevant schoolwide positive behavior support strategies. Behavioral Disorders, 40(4), 251-260.

Feil, E., Small, J., Forness, S., \& Serna, L. (2005). Using Different Measures, Informants, and Clinical Cut-Off Points to Estimate Prevalence of Emotional or Behavioral Disorders in Preschoolers: Effects on Age, Gender and Ethnicity. Behavioral Disorders, 30, 375-391.

Filcheck, H. A. (2004). Evaluation of a whole-class token economy to manage disruptive behavior in preschool classrooms (Doctoral dissertation). Retrieved from PsycINFO.

Filcheck, H. A., \& McNeil, C. B. (2004). The use of token economies in preschool classrooms: Practical and philosophical concerns. Journal of Early and Intensive Behavior Intervention, 1, 94-104.

Filcheck, H. A., McNeil, C. B., Greco, L. A. \& Bernard, R. S. (2004). Using a wholeclass token economy and coaching of teacher skills in a preschool classroom to manage disruptive behavior. Psychology in the Schools, 4, 351-361.

Fox, L., Carta, J., Strain, P. S., Dunlap, G., \& Hemmeter, M. L. (2010). Response to intervention and the pyramid model. Infants \& Young Children, 23(1), 3-13.

Fox, L., \& Little, N. (2001). Starting early: School-wide behavior support in a community preschool. Journal of Positive Behavior Interventions, 3, 251-254. 
Gilliam, W. S. (2005). Prekindergarteners Left Behind: Expulsion Rates in State Prekindergarten Systems. (Policy Brief Series No. 3). Foundation for Child Development.

Gresham, F. M., \& Gresham, G. N. (1982). Interdependent, Dependent, and Independent Group Contingencies for Controlling Disruptive Behavior. The Journal of Special Education, 16(1), 101-110.

Hawken, L., \& Johnston, S. (2007). Preventing Severe Problem Behavior in Young Children: The Behavior Education Program, 4(3), 599-613.

Hawken, L. S., O’Neill, R. E., \& MacLeod, K. S. (2011). An Investigation of the Impact of Function of Problem Behavior on Effectiveness of the Behavior Education Program (BEP). Education and Treatment of Children, 34(4), 551-574.

Hayes, L. A. (1976). The use of group contingencies for behavioral control: a review. Psychological Bulletin, 83(4), 628-48.

Heering, P., \& Wilder, D. (2006). The Use of Dependent Group Contingencies to Increase On-Task Behavior in Two General Education Classrooms. Education and Treatment of Children, (3), 459-468.

Hemmeter, M. L., Fox, L., Jack, S., \& Broyles, L. (2007). A program-wide model of positive behavior support in early childhood settings. Journal of Early Intervention, 29(4), 337-355.

Hemmeter, M. L., \& Santos, R. M. (2008). Preparing Early Childhood Educators to Address Young Children's Social-Emotional Development and Challenging Behavior. Journal of Early Intervention, 321-341. 
Herman, S., \& Tramontana, J. (1971). Instructions and Group Versus Individual Reinforcement In Modifying Disruptive Group Behavior. Journal of Applied Behavior Analysis, 2(2), 113-119.

Hoag, J. (2007). Effects of mystery motivators vs. expected reinforcers on disruptive behavior in preschoolers. Dissertation Abstracts International: Section B. The Sciences and Engineering, 67(10-B), 6041.

Hoover, S. D., Kubicek, L. F., Rosenberg, C. R., Zundel, C., \& Rosenberg, S. A. (2012). Influence of behavioral concerns and early childhood expulsions on the development of early childhood mental health consultation in Colorado. Infant Mental Health Journal, 33, 246-255.

Horner, R. H., Carr, E. G., Halle, J., McGee, G., Odom, S., \& Wolery, M. (2005). The use of single-subject research to identify evidence-based practice in special education. Exceptional children, 71(2), 165-179.

Hunt, B. M. (2013). Using the good behavior game to decrease disruptive behavior while increasing academic engagement with a head start population (Doctoral dissertation). The University of Southern Mississippi, Hattiesburg, MS.

Individuals with Disabilities Education Improvement Act of 2004, Pub. L. No. 108-446 § 300.115 (2004).

Kazdin, A. E., \& Geesey, S. (1977). Simultaneous-treatment design comparisons of the effects of earning reinforcers for one's peers versus oneself. Behavior Therapy, 8 , 682-693.

Kohler, F. W., Strain, P. S., Hoyson, M., Davis, L., Donina, W. M., \& Rapp, N. (1995). Using group-oriented contingency to increase social interactions between children 
with autism and their peers: A preliminary analysis of corollary supportive behaviors. Behavior Modification, 19, 10-32.

Kratochwill, T. R., Hitchock, J., Horner, R. H., Levin, J. R., Odom, S. L., Rindskopf, D.M. \& Shadish, W.R. (2010). Single-case designs technical documentation. Retrived from What Works Clearninghouse website: http://ies.ed.gov/ncee/wwc/pdf/wwc_scd.pdf.

Kratochwill, T. R., Hitchcock, J. H., Horner, R. H., Levin, J. R., Odom, S. L., Rindskopf, D. M. \& Shadish, W. (2013). Single-case intervention research design standards. Remedial and Special Education, 34, 26-38.

Labrot, Z., Dufrene, B., Radley, K., \& Pasqua, J. (2016). Evaluation of a Modified Check-in / Check-out Intervention for Young Children. Perspectives in Early Education, 1(1), 143-165.

Larmar, S., \& Gatfield, T. (2006). Management of Conduct Problems in Young Children. International Journal of Learning, 13(1), 149-153.

Lavigne, J. V, Lebailly, S. A., Hopkins, J., Gouze, K. R., \& Binns, H. J. (2009). The prevalence of ADHD, ODD, depression, and anxiety in a community sample of 4year-olds. Journal of Clinical Child and Adolescent Psychology, 38, 315-328.

Ling, S. M., \& Barnett, D. W. (2013). Increasing Preschool Student Engagement During Group Learning Activities Using a Group Contingency. Topics in Early Childhood Special Education, 33(3), 186-196.

Litow, L., \& Pumroy, D. K. (1975). A brief review of classroom group-oriented contingencies. Journal of Applied Behavioral Analysis, 8, 341-347. 
Little, S. G., Akin-Little, A., \& O’Neill, K. (2015). Group Contingency Interventions with Children-1980-2010: A Meta-Analysis. Behavior Modification, 39(2), 322341.

Maggin, D. M., Johnson, A. H., Chafouleas, S. M., Ruberto, L. M., \& Berggren, M. (2012). A systematic evidence review of school-based group contingency interventions for students with challenging behavior. Journal of School Psychology, 50(5), 625-54.

Martens, B. K., Witt, J. C., Elliott, S. N., \& Darveaux, D. X. (1985). Teacher judgments concerning the acceptability of school-based interventions. Professional Psychology: Research and Practice, 16(2), 191-198.

Maus, M. (2007). Independent group contingencies for reducing disruptive behavior in preschoolers with PDD-NOS (Doctoral dissertation). Hofstra University, Hempstead, N.Y.

Molloy, L. E., Moore, J. E., Trail, J., Van Epps, J. J., \& Hopfer, S. (2013). Understanding real world implementation quality and "active ingredients" of PBIS. Prevention Science, $14,593-605$.

Moore, L. A., Waguespack, A. M., Wickstrom, K. F., Witt, J. C., \& Gaydos, G. R. (1994). Mystery motivator: An effective and time efficient intervention. School Psychology Review, 23, 106-118.

Murnane, Richard J., \& Jennifer L. Steele. 2007. "What Is the Problem? The Challenge of Providing Effective Teachers for All Children.” The Future of Children, 17(1), 15-43. 
Murphy, K. A., Theodore, L. A., Aloiso, D., Alric-Edwards, J. M., \& Hughes, T. L. (2007). Interdependent group contingency and mystery motivators to reduce preschool disruptive behavior. Psychology in the Schools, 44(1), 53-63.

Parker, R. I., Vannest, K. J., Davis, J. L., \& Sauber, S. B. (2011). Combining nonoverlap and trend for single-case research: Tau-U. Behavior Therapy, 42(2), 284-299.

Pasqua, J. L., Dart, E. H., \& Radley, K. C. (2016). Behavior Interventions in the Restroom: Flushing Away Noise. Journal of Applied School Psychology, 32(3), $268-286$.

Pokorski, E. A., Barton, E. E., \& Ledford, J. R. (2016). A Review of the Use of Group Contingencies in Preschool Settings. Topics in Early Childhood Special Education, 36(1), 1-12.

Poole, V. Y., Dufrene, B. ., Sterling, H. E., Tingstrom, D. H., \& Hardy, C. M. (2012). Classwide Functional Analysis and Treatment of Preschoolers' Disruptive Behavior. Journal of Applied School Psychology, 28(2), 155-174.

Powell, D., Fixsen, D., Dunlap, G., Smith, B., \& Fox, L. (2007). A synthesis of knowledge relevant to pathways of service delivery for young children with or at risk of challenging behavior. Journal of Early Intervention, 29, 81-106.

Pretti-Frontczak, K., Carta, J., Dropkin, E., Fox, L., Grisham-Brown, J., Edwards, C., Sandall, S., \& Childhood, E. (2013). Frameworks for Response to Intervention in Early Childhood: Description and Implications. Communication Disorders Quarterly, 35, 108-119. 
Qi, C., \& Kaiser, A. P. (2003). Behavior problems of preschool children from lowincome families: A review of the literature. Topics in Early Childhood Special Education, 23, 188-216.

Qi, C. H., Kaiser, A. P., \& Milan, S. (2006). Children's behavior during teacher-directed and child-directed activities in Head Start. Journal of Early Intervention, 28(2), 97-110.

Quesenberry, A. C., Hemmeter, M. L., \& Ostrosky, M. M. (2011). Addressing challenging behaviors in Head Start: A closer look at program policies and procedures. Special Education, 30, 209-220.

Radley, K. C., O’Handley, R. D., \& LaBrot, Z. C. (2015). A comparison of momentary time sampling and partial-interval recording for assessment of effects of social skills training. Psychology in the Schools, 52(4), 363-378.

Raver, C. C., Jones, S. M., Li-Grining, C., Zhai, F., Metzger, M. W., \& Solomon, B. (2009). Targeting children's behavior problems in preschool classrooms: A cluster-randomized controlled trial. Journal of Consulting and Clinical Psychology, 77(2), 302-316.

Reitman, D., Murphy, M. A., Hupp, S. D. A., \& O’Callaghan, P. M. (2004). Behavior change and perceptions of change: Evaluating the effectiveness of a token economy. Child \& Family Behavior Therapy, 26, 17-36.

Riley-Tillman, T. C., Chafouleas, S. M., Briesch, A. M., \& Eckert, T. L. (2008). Daily Behavior Report Cards and Systematic Direct Observation: An Investigation of the Acceptability, Reported Training and Use, and Decision Reliability Among School Psychologists. Journal of Behavioral Education, 17(4), 313-327. 
Riley-Tillman, T. C., Methe, S. A., \& Weegar, K. (2009). Examining the use of direct behavior rating on formative assessment of class-wide engagement: A case study. Assessment for Effective Intervention, 34(4), 224-230.

Schweinhart, L. (1994). Lasting Benefits of Preschool Programs, 1-4. ERIC Digest. Retrieved from ERIC database. (ED365478)

Shapiro, E. S., Albright, T. S., \& Ager, C. L. (1986). Group versus individual contingencies in modifying two disruptive adolescents' behavior. Professional School Psychology, 1, 105-116.

Skinner, C. H., Skinner, A. L., \& Burton, B. (2009). Applying group-oriented contingencies in classrooms. In K. A. Akin-Little, S. G. Little, M. Bray, \& T. Kehle (Eds.), Behavioral interventions in schools: Evidence-based positive strategies (pp. 157-170). Washington, DC: American Psychological Association.

Snell, M. E., Berlin, R. A., Voorhees, M. D., Stanton-Chapman, T. L., \& Hadden, S. (2012). A Survey of Preschool Staff Concerning Problem Behavior and Its Prevention in Head Start Classrooms. Journal of Positive Behavior Interventions, $14(2), 98-107$.

Stage, S. A., \& Quiroz, D. R. (1997). A meta-analysis of interventions to decrease disruptive classroom behavior in public education settings. School Psychology Review, 26, 333-368.

Steed, E. A., Pomerleau, T. M., \& Horner, R. H. (2012). Preschool-wide Evaluation Tool: Research Edition. Baltimore, MD: Paul Brookes Publishing Co. 
Stormont, M., Lewis, T. J., \& Beckner, B. (2005). Developmentally continuous positive behavior support systems: Applying key features in preschool settings. Teaching Exceptional Children, 37, 42-48.

Stormont, M., Reinke, W., \& Herman, K. (2011). Teachers' Knowledge of EvidenceBased Interventions and Available School Resources for Children with Emotional and Behavioral Problems. Journal of Behavioral Education, 20(2), 138-147.

Sugai, G., \& Horner, R. H. (2006). A promising approach for expanding and sustaining school-wide positive behavior support. School Psychology Review, 35, 245-259.

Sugai, G., \& Horner, R. H. (2002). The evolution of discipline practices: School-wide positive behavior supports. Child \& Family Behavior Therapy, 24, 23-50.

Swiezy, N. B., Matson, J. L., \& Box, P. (1992). The good behavior game: A token reinforcement system for preschoolers. Child \& Family Behavior Therapy, 14, 21-32.

Theodore, L., Bray, M., \& Kehle, T. (2004). A Comparative Study of Group Contingencies and Randomized Reinforcers to Reduce Disruptive Classroom Behavior. School Psychology Quarterly, 19(3), 253-271.

Theodore, L. A., Bray, M. A., Kehle, T. J., \& Dioguardi, R. J. (2004). Contemporary Review of Group-Oriented Contingencies for Disruptive Behavior. Journal of Applied School Psychology. 20(1), 79-101.

Tiano, J. D., Fortson, B. L., McNeil, C. B., \& Humphreys, L. A. (2005). Managing Classroom Behavior of Head Start Children Using Response Cost and Token Economy Procedures. Journal of Early and Intensive Behavior Intervention, 2(1), 12. 
Tillery, A., Varjas, K., Meyers, J., \& Collins, A. S. (2010). General Education Teachers' Perceptions of Behavior Management and Intervention Strategies. Journal of Positive Behavior Interventions, 12(2), 86-102.

Tingstrom, D. H., Sterling-Turner, H. E., \& Wilczynski, S. M. (2006). The good behavior game: 1969-2002. Behavior Modification, 30(2), 225-53.

U.S. Department of Health and Human Services, Administration for Children and Families, Office of Planning Research and Evaluation. (2010-2015). National survey of early care and education. Washington, DC. Available at http://www.acf/hhs/gov/programs/opre/research/project/national-survey-of- earlycare-and-education-nsece-2010-2014.

Vannest, K. J., \& Ninci, J. (2015). Evaluating Intervention Effects in Single-Case Research Designs. Journal of Counseling \& Development. 93(4), 403-411.

Vinh, M., Strain, P., Davidson, S., \& Smith, B. J. (2016). One state's systems change efforts to reduce child care expulsion: Taking the Pyramid Model to Scale. Topics in Early Childhood Special Education. Advanced online publication.

Volpe, R. J., \& Briesch, A. M. (2012). Generalizability and dependability of single-item and multiple-item direct behavior rating scales for engagement and disruptive behavior. School Psychology Review, 41(3), 246-261.

Von Brock, M. B., \& Elliott, S. N. (1987). Influence of treatment effectiveness information on the acceptability of classroom interventions. Journal of School Psychology, 25(2), 131-144.

Voorhees, M. D., Walker, V. L., Snell, M. E., \& Smith, C. G. (2013). A Demonstration of Individualized Positive Behavior Support Interventions by Head Start Staff to 
Address Children's Challenging Behavior. Research and Practice for Persons with Severe Disabilities, 38(3), 173-185.

Webster-Stratton, C., \& Hammond, M. (1998). Conduct problems and level of social competence in Head Start children: prevalence, pervasiveness, and associated risk factors. Clinical Child and Family Psychology Review, 1(2), 101-24.

Webster-Stratton, C., Reid, M. J., \& Hammond, M. (2004). Treating children with earlyonset conduct problems: Intervention outcomes for parent, child, and teacher training. Journal of Clinical Child and Adolescent Psychology, 33, 105-124.

Webster-Stratton, C., Reid, M. J., \& Hammond, M. (2001). Preventing conduct problems, promoting social competence: A parent and teacher training partnership in Head Start. Journal of Clinical Child Psychology, 30(3), 283-302.

Webster-Stratton, C., Reid, J. M., \& Stoolmiller, M. (2008). Preventing conduct problems and improving school readiness: Evaluation of the Incredible Years Teacher and Child Training Programs in high-risk schools. Journal of Child Psychology and Psychiatry, 49, 471-488.

Whitted, K. (2011). Understanding how social and emotional skill deficits contribute to school failure. Preventing School Failure, 55(1), 10-16.

Wichstrom, L., Berg-Nielsen, T. S., Angold, A., Egger, H. L., Solheim, E., \& Sveen, T. H. (2012). Prevalence of psychiatric disorders in preschoolers. The Journal of Child Psychology and Psychiatry, 53(6), 695-705. 
Worcester, J. A., Nesman, T. M., Mendez, R. L., \& Keller, H. R. (2008). Giving voice to parents of young children with challenging behavior. Exceptional Children, 74, $509-525$. 